Biologie Aujourd'hui, 209 (1), 35-61 (2015)

(C) Société de Biologie, 2015

DOI: $10.1051 / \mathrm{jbio} / 2015011$

\title{
Les gènes et les protéines qui contrôlent la voie de sécrétion*
}

\author{
Randy Schekman \\ Department of Molecular and Cell Biology, Howard Hughes Medical Institute, University of California, Berkeley, USA
}

Auteur correspondant : Randy Schekman, schekman@berkeley.edu

\section{Introduction}

George Palade a partagé le Prix Nobel 1974 avec Albert Claude et Christian De Duve pour leurs travaux pionniers sur la caractérisation des organites étroitement coordonnés au cours du processus de sécrétion dans les cellules et les tissus de mammifères. Ces trois précurseurs ont fondé le domaine moderne de la Biologie Cellulaire et inventé des outils pour fractionner les cellules et utiliser la microscopie électronique à transmission sur coupes ultrafines. Palade en particulier, grâce à son génie, a révélé l'organisation de la voie de sécrétion. Il a découvert le ribosome et montré qu'il était posé à la surface du réticulum endoplasmique $(\mathrm{RE})$, où il était engagé dans la translocation vectorielle des polypeptides nouvellement synthétisés. Dans une analyse très élégante et techniquement virtuose, son groupe a utilisé des aminoacides radioactifs dans un système de pulse/chase pour montrer, par autoradiographie de coupes ultrafines, que les protéines sécrétoires cheminent séquentiellement du RE à travers l'appareil de Golgi dans les granules de sécrétion, qui à leur tour déchargent leur contenu à la surface cellulaire par fusion de membrane. Palade a mis en évidence le rôle des vésicules comme transporteur entre les compartiments et a formulé l'hypothèse selon laquelle les membranes modélisent leur propre production, plutôt que de se former par un processus de biogenèse de novo (Palade, 1975).

Comme étudiant à l'Université, j'ignorais les développements importants qui avaient lieu en biologie cellulaire; tout de même j'avais entendu parler du travail de Palade pendant ma première année d'études dans le département de biochimie de Stanford. Palade était un ami intime de mon directeur Arthur

\footnotetext{
* La Fondation Nobel (www.Nobelprize.org) nous a autorisés à publier cette traduction de la conférence donnée par le Pr. Schekman lors de la remise du Prix Nobel 2013. Nous l'en remercions vivement ainsi que le Pr. Schekman. Les figures ont été reproduites dans la version originale de la conférence Nobel et les légendes y sont donc en anglais.
}

Kornberg, qui avait obtenu le Prix Nobel en 1959 pour sa découverte de l'ADN polymérase, la première enzyme reconnue pour être construite selon un modèle, dans ce cas un brin d'ADN (Kornberg et al., 1956). À première vue, Kornberg et Palade avaient peu de choses en commun. Palade était un anatomiste classique et un physiologiste pour qui le microscope électronique était l'outil d'analyse essentiel. Kornberg était un biochimiste classique qui se préoccupait passionnément de la chimie de la vie, qu'il sondait exclusivement par l'étude d'enzymes purifiées. Toutefois, vers la fin des années 1960, lorsque l'étude de la synthèse de l'ADN commença à se focaliser sur le rôle possible d'une surface membranaire dans l'organisation de la ségrégation des chromosomes en voie de réplication, Kornberg a développé un vif intérêt pour la biochimie des membranes et en 1969, l'année précédant mon arrivée, Kornberg avait visité plusieurs laboratoires de biologie des membranes, y compris celui de Palade, qui était alors à l'Université Rockfeller. À son retour, Kornberg a porté son attention sur les enzymes membranaires, avec l'espoir qu'une surface membranaire pourrait fournir le chaînon crucial du problème de la réplication de l'ADN. Juste à ce moment, pendant l'été 1969, ce domaine était ébranlé par la découverte de John Cairns, alors directeur du laboratoire de Cold Spring Harbor, selon laquelle l'ADN polymérase de Kornberg n'était pas nécessaire à la réplication des chromosomes. Je suis allé à Cold Spring Harbor cet été-là et j'ai été emporté par l'excitation qui entourait l'isolement, réussi par Cairns, d'un mutant pol1 d'E. coli qui n'avait pas d'activité polymérase, croissait pourtant normalement et était sensible à l'irradiation UV, signe évident que la polymérase classique ne pouvait être l'enzyme responsable de la réplication, mais jouait plutôt un rôle dans la réparation de l'ADN (De Lucia \& Cairns, 1969).

\section{Puissance de la génétique et de la biochimie combinées}

Kornberg, figure dominante, était doué d'une forte personnalité et d'une intelligence supérieure. 
Sa focalisation sur la chimie des enzymes a façonné une génération d'étudiants qui travaillaient sur l'enzymologie de l'ADN, y compris plusieurs anciens postdoctorants et associés qui l'ont rejoint pour former le noyau de ce qui devait devenir l'éminent département de biochimie de l'École de Médecine de Stanford, où il s'installa en quittant l'Université de Washington à Saint Louis en 1959, l'année où il reçut le Prix Nobel. À l'aide de l'ADN-polymérase purifiée, Kornberg a prouvé que celle-ci utilisait les instructions d'un brin modèle et copiait l'ADN dans la direction antiparallèle, comme c'était prédit dans le schéma du duplex d'ADN de Watson et Crick (Josse et al., 1961). La preuve la plus convaincante que l'ADN polymérase pouvait être l'enzyme de réplication vint en 1967 avec la démonstration que la polymérase seule copiait le simple brin circulaire du bactériophage $\varphi$ X174 pour édifier un brin complémentaire, qui servait à son tour de matrice pour un brin d'ADN viral infectieux (Goulian \& Kornberg, 1967; Goulian et al., 1967). Ainsi l'enzyme pouvait se servir des informations apportées par un modèle d'environ 5500 nucléotides et construire son complément, essentiellement sans erreur, reproduisant ainsi le cycle infectieux dans une cellule vivante.

Cependant, se fondant sur plusieurs caractéristiques de la polymérase, certains chercheurs restaient sceptiques sur le fait qu'elle puisse être l'authentique enzyme de réplication. L'élongation de la chaîne d'ADN était très lente par comparaison à la progression de la fourchette de réplication chromosomique. L'enzyme avait des propriétés qui suggéraient une capacité à réparer les dommages de l'ADN, par exemple en excisant des dimères de thymidine d'ADN isolé à partir de cellules exposées à la lumière ultraviolette (Kelly et al., 1969). Un autre caractère étonnant était la nécessité d'un oligonuléotide complémentaire formant un duplex court, servant à lancer la polymérase à partir d'un 3'OH apporté par le primer (Goulian \& Kornberg, 1967). Néanmoins, une enzyme comme la polymérase d'E. coli est codée par le bactériophage T4 et, dans ce cas, des mutations dans le gène de la polymérase du phage montrent que celui-ci est requis pour la réplication du chromosome viral (De Waard et al., 1965).

Tout à fait indépendamment, des généticiens spécialistes des bactéries ont trouvé des gènes essentiels à la réplication chromosomique en isolant et caractérisant des mutations température-sensibles $(t s)$, qui stoppent la synthèse de l'ADN quand les cellules sont portées à $42{ }^{\circ} \mathrm{C}$ (Fangman \& Novick, 1968 ; Hirota et al., 1968). Les cellules qui portent les mutations dna peuvent croître à $30^{\circ} \mathrm{C}$ mais cessent de pousser à $42{ }^{\circ} \mathrm{C}$. Les gènes dna sont donc des candidats pour la machinerie de réplication authentique tout à fait distincts du gène pol1, identifié comme non essentiel dans le mutant de Cairns.

L'alliance de la génétique et la biochimie s'est faite pour la première fois par un détour du destin, lors de la découverte par Tom Kornberg, le second fils d'Arthur, alors étudiant dans le laboratoire de Malcolm Gefter à l'Université de Columbia, d'une autre activité de réplication dans les lysats du mutant de Cairns (Kornberg \& Gefter, 1970). Gefter et Cairns découvrirent ensuite que la polymérase authentique est codée par le gène dnaE, l'un des quelque six gènes alors connus pour leur contribution essentielle à la réplication de l'ADN (Gefter et al., 1971).

En 1970, j'ai rejoint le laboratoire d'Arthur, alors profondément influencé par deux lignes de recherche, d'une part l'enzymologie telle qu'elle était pratiquée par l'école de Kornberg, et d'autre part, la biologie moléculaire et la génétique, décrites au plus près dans le manuel de James Watson, Biologie Moléculaire du Gène (Watson, 1966). J'avais lu la première édition de ce livre et m'étais délecté des détails pendant ma première année à l'UCLA; bien qu'attiré par l'approche de Kornberg pour ma formation pré-doctorale, je pensais qu'il était nécessaire que la génétique et la physiologie cellulaire viennent en complément de la biochimie.

Un précédent remarquable plaidait pour les avantages de cette combinaison de la génétique et de la biochimie; c'était le travail pionnier de Robert Edgar, un généticien des bactéries qui avait disséqué le processus d'assemblage du phage T4, grâce à l'isolement de mutations des gènes qui codent pour les sous-unités de l'enveloppe du phage (Epstein et al., 1963), et de William Wood, un nouveau collègue de faculté d'Epstein à Cal Tech. Wood avait fait son apprentissage avec Paul Berg, un ancien postdoc de Kornberg, alors son collègue dans le nouveau département de Biochimie de Stanford. À Cal Tech, à l'automne 1965, Wood et Edgar avaient réalisé ensemble une expérience classique de biologie moléculaire. Edgar avait trouvé que certains des mutants de l'enveloppe virale accumulaient des têtes et des queues virales incomplètes à l'intérieur des cellules infectées. Edgar utilisa alors le test standard de complémentation génétique cis/trans, développé plus tôt par Seymour Benzer en vue de caractériser les gènes rII du phage (Benzer, 1957), pour identifier les gènes impliqués dans la morphogenèse du phage T4. Wood a imaginé que la complémentation biochimique pourrait être réalisée en mélangeant des extraits de cellules infectées par différents phages mutés pour l'assemblage. Et effet, en commençant avec des extraits distincts qui n'avaient pratiquement pas de virions infectieux détectables par le test des plaques de phage, Edgar et Wood ont constaté que le mélange des lysats de mutants génétiquement complémentaires 
(i.e., complémentation biochimique) produisait une multiplication par 1000 des particules infectieuses (Edgar \& Wood, 1966). À partir de là, l'équipe a identifié les intermédiaires d'assemblage fonctionnel et a cartographié les modalités de l'assemblage du virus. Il était clair que cette approche avait le potentiel nécessaire pour disséquer des voies complexes et pour révéler des détails moléculaires qui n'auraient pas été élucidés à l'aide d'une analyse strictement génétique ou biochimique.

En 1971, Doug Brutlag, un étudiant doué du laboratoire d'Arthur, a découvert que la conversion du simple brin circulaire du phage M13 en forme réplicative double brin était bloquée dans les cellules infectées par un inhibiteur de la transcription de l'enzyme ARN polymérase, et ceci en dépit du fait qu'aucune expression des gènes ni de l'hôte ni du virus n'est requise au premier stade de la réplication chromosomique. Brutlag et Kornberg ont suggéré que l'ARN polymérase fournissait peut-être le primer manquant pour initier la croissance d'une chaîne d'ADN (Brutlag et al., 1971). Brutlag mit alors en ouvre une réaction de réplication dans un lysat concentré de cellules d'E. coli non infectées et découvrit que cette expérience démontrait à nouveau la présence nécessaire d'ARN polymérase lors de la conversion des matrices simple-brin du M13 en duplex réplicatifs (Wickner et al., 1972). Un extrait concentré de E. coli similaire avait été obtenu dans le laboratoire de Friedrich Bonhoeffer à Tübingen en Allemagne; un des post-docs de Bonhoeffer, Baldomero Olivera, avait montré que cet extrait était capable de répliquer le brin circulaire simple du $\varphi$ X174 (Olivera \& Bonhoeffer, 1972). Les deux lysats concentrés contenaient des protéines membranaires et cytosoliques et il paraissait vraisemblable que la réaction exigerait une contribution membranaire. Toutefois, au même moment, Bruce Alberts, alors à l'Université de Princeton, avait observé que les lysats cytosoliques solubles de cellules infectées par le phage $\mathrm{T} 4$ répliquaient le DNA de T4; appliquant le raisonnement de Wood et Edgar, Jack Barry et Alberts mirent en évidence la complémentation biochimique des fractions protéiques solubles obtenues à partir de différentes cellules T4 mutantes pour la réplication (Barry \& Alberts, 1972).

À Stanford, un nouveau post-doc dans le groupe de Kornberg, William (Bill) Wickner, a découvert que le lysat capable de répliquer l'ADN du M13 pouvait être centrifugé et produire une fraction soluble sans perte de l'activité de réplication (Wickner et al., 1972). Tout l'intérêt pour les membranes et la réplication de l'ADN sembla disparaître avec ce résultat.

Je me suis joint à l'effort initié par Brutlag et Kornberg d'abord à propos de la réplication de l'ADN de M13 puis, grâce à la réaction acellulaire mise au point par Brutlag, j'ai montré que la formation du double brin du $\varphi$ X174 était insensible à la drogue qui bloque l'ARN polymérase standard, ce qui suggérait l'existence d'une ARN polymérase alternative pour la synthèse du primer (Schekman et al., 1972; Wickner et al., 1972). À l'Université de Harvard David Denhardt, avec qui j'avais travaillé un été, avait rapporté que la formation du double brin du $\varphi$ X174 dépendait du gène $d n a B$ d'E. coli. Il semblait donc possible que la réaction acellulaire fournisse un test fonctionnel pour la purification de la protéine dnaB et pour les autres protéines dna. C'était bien le cas et cette réaction a permis la détection et le fractionnement de l'ensemble complet des protéines de réplication d'E. coli (Schekman et al., 1974). L'une des protéines d'ADN, DnaG, s'est révélée catalyser une nouvelle réaction de synthèse de l'ARN qui fournit le primer de $\varphi \mathrm{X} 174$ comme celui de la réplication de la fourchette chromosomique de $E$. coli. Je prévoyais donc que les approches génétique et biochimique pourraient être essentielles pour élucider d'autres processus cellulaires complexes.

Le cycle de division cellulaire représentait un de ces processus complexes qu'on commençait tout juste à sonder par des approches de génétique moléculaire. J'étais particulièrement fasciné par les efforts de Leland Hartwell qui avait exploité les outils génétiques classiques utilisés sur la levure Saccharomyces cerevisiae, pour tester la série d'évènements essentiels qui conduisent à la division cellulaire de la levure. La clé était un assortiment de gènes, identifiés par l'isolement de mutations $t s$ létales, qui ont attiré l'attention sur des éléments de contrôle décisifs pour la progression du cycle cellulaire (Hartwell et al., 1973). Les découvertes de génétique moléculaire ultérieures de Paul Nurse, Tim Hunt et d'autres ont éclairé la base moléculaire de ce contrôle. Ici aussi, les conceptions moléculaires acquises grâce à une approche de génétique classique se sont montrées cruciales pour la découverte d'une protéine kinase qui contrôle le déclic d'initiation du cycle de division cellulaire et intervient ensuite de manière répétitive dans les transitions successives de tout le cycle cellulaire. Une voie semblable chez les mammifères a été conservée au cours d'un milliard d'années d'évolution. D'après cela, il semblait probable que les études sur la levure permettraient d'anticiper la compréhension de beaucoup, sinon de tous les processus intracellulaires essentiels des eukaryotes.

\section{Étudier les membranes biologiques comme un assemblage macromoléculaire}

Alors que les réactions de réplication qu'il analysait n'étaient pas directement en rapport avec des membranes, Kornberg restait intéressé par la 
problématique de purification des enzymes membranaires et il était donc impatient d'accueillir un enzymologiste de membranes expérimenté, Bill Wickner, qui entra dans son labo comme post-doc en 1971. Bill avait fait ses études de médecine avec Eugene Kennedy à l'École de Médecine de Harvard; il y perdit son intérêt pour la médecine clinique mais développa une passion durable pour les membranes biologiques. Lui et moi passions des heures à discuter de notre travail, mais ce qui fut important, c'est que j'appris auprès de lui beaucoup de ce qui était connu ou non à propos de la manière dont les membranes se construisent. Dans ce contexte, j'ai lu les travaux de Palade et de ses associés David Sabatini et Philip Siekevitz, qui exploraient alors le mécanisme de la translocation membranaire vectorielle des protéines sécrétoires, durant leur élaboration sur les ribosomes associés au RE (Redman \& Sabatini, 1966; Redman et al., 1966). Le département de biochimie de Standford était un des pôles d'attraction pour les visites de toutes les personnalités de premier plan de la biologie moderne. J'ai rencontré Hartwell et deux autres hommes remarquables qui représentaient des approches distinctes de l'étude de la fonction membranaire : l'un, Efraïm Racker, partageait la passion d'Arthur pour les enzymes et disséquait le mécanisme de la phosphorylation oxydative des mitochondries et l'autre, Daniel Koshland, avait exploité une approche génétique ouverte par Julius Adler pour sonder le mécanisme du chimiotactisme bactérien, un processus intimement lié à la détection de gradients chimiques à la surface des bactéries.

Alors que je réfléchissais à mon futur projet de recherche, j'étais motivé par le désir de quitter le domaine de la réplication de l'ADN, tout en m'en appropriant les outils et la logique qui avaient propulsé le groupe de Kornberg vers la dissection et la reconstitution des enzymes du processus de réplication. Comme j'achevais mon travail pré-doctoral en 1974, une révolution en ingénierie génétique et en recombinaison d'ADN faisait tout juste ses débuts, en grande partie par suite du travail de Stanley Cohen, microbiologiste à Stanford, et d'Herbert Boyer, biochimiste à l'UCSF. Les outils du clonage moléculaire étaient en vue, il était donc tentant de se demander comment ils pouvaient être appliqués à découvrir des gènes essentiels dans d'innombrables processus cellulaires.

Pourtant l'activité frénétique concentrée sur tout ce qui concernait l'ADN m'était inconfortable. Je ne tirais aucun plaisir de la pression de compétition avec d'autres laboratoires faisant les mêmes expériences. J'ouvrais nerveusement chaque nouveau numéro des Proceedings of the National Academy of Sciences $(P N A S)$ en cherchant si nos concurrents ne nous avaient pas battus par des découvertes clés. Profiter de l'influence de Kornberg avait ses avantages, mais en réfléchissant à ma carrière, je décidais de partir dans une nouvelle direction où j'aurais une chance d'établir ma propre identité, plutôt que de dépendre, ou d'être éclipsé par la réputation de Kornberg.

Alors que je cherchais une voie de recherche nouvelle, j'ai été impressionné par le travail de S. Jonathan Singer à l'Université de Californie à San Diego, en particulier par son article très influent sur le modèle en mosaïque fluide de la structure de la membrane (Singer \& Nicholson, 1972). Il y avait là une synthèse grandiose qui apportait un cadre conceptuel, permettant d'imaginer la manière dont une membrane pouvait être construite. Le labo de Singer avait rassemblé des outils pour explorer la topologie des membranes au microscope électronique. Son associé Kiyoteru Tokuyasu avait mis au point une remarquable méthode de cryomicroscopie électronique pour détecter les antigènes sur les membranes (Tokuyasu, 1973). Il avait ainsi été démontré que les glycanes dans les glycoprotéines et les glycolipides sont disposés asymétriquement sur la surface extracellulaire des globules rouges et à la surface luminale des membranes du $\mathrm{RE}$, concrétisant ainsi la prédiction que le mouvement des protéines hydrophiles et des glycanes à travers la bicouche lipidique était improbable du point de vue thermodynamique, mais expliquant en même temps comment l'asymétrie de la membrane plasmique peut se construire au début du parcours sécrétoire (Hirano et al., 1972). Singer jouissait de la chaleureuse approbation de mes mentors à Stanford, si bien que je me mis en route avec ma jeune femme Nancy, que j'avais rencontrée grâce à mon amitié avec Bill Wickner, pour rejoindre le labo de Singer comme post-doc à l'automne de 1974.

Singer était si différent de Kornberg que j'en subis une sorte de choc culturel, en essayant de repérer un projet de recherche qui nous intéresserait tous les deux. Alors qu'il avait fait sa carrière comme physicochimiste, il avait évolué en biologiste cellulaire centré sur les questions d'organisation cellulaire. J'étais avide d'utiliser la stratégie de reconstitution de Kornberg pour explorer quelques aspects de l'assemblage de la membrane ou de l'endocytose, mais Singer me pressait d'entreprendre une étude morphologique au microscope électronique. Bien sûr, il était important d'apprendre une nouvelle discipline en même temps qu'une nouvelle stratégie, si bien que je choisis un projet qui consistait à investiguer le comportement inhabituel des érythrocytes humains néonataux qui, à la différence des globules rouges matures, sont incapables d'internaliser les molécules d'anticorps ou de lectines agrégées à leur surface (Schekman \& Singer, 1976). Je trouvais ce travail frustrant et, en dépit de la patience de Tokuyasu, mes talents techniques pour la confection de coupes ultrafines pour le microscope électronique laissaient beaucoup à désirer. Cela 
prit deux ans pour obtenir un précieux échantillon témoin Rh- de sang du cordon. La perspective d'une compréhension moléculaire satisfaisante de ce processus semblait lointaine et ma dépendance du service local d'accouchement pour l'obtention de sang de cordon ramenait la progression au pas de l'escargot. J'étais gâté par mon expérience précédente avec les microorganismes, et les approches lentes et incommodes alors nécessaires pour obtenir des échantillons humains ou même des cellules mammaliennes cultivées ne pouvaient tout simplement pas se comparer. J'avais donc du temps pour lire et réfléchir, ce qui a été probablement le bénéfice majeur des mes années postdoctorales.

Peu après mon arrivée dans le labo de Singer, le meeting annuel de la Société Américaine pour la Biologie cellulaire (ASCB) se réunissait à San Diego. À l'époque, l'ASCB était une petite organisation très personnalisée, plus artisanale que ne l'était la plus grande et plus influente Société Américaine pour la Biologie Chimique (ASBC, plus tard renommée l'ASBMB). Palade venait de rentrer de Stockholm pour donner une conférence spéciale à une foule idolâtre qui s'était levée pour une ovation debout à la fin de sa présentation. Bien que j'ai su à cette époque, et appris plus encore par la suite, que Palade était un intellectuel brillant aux intérêts très vastes, je quittais ce meeting avec le sentiment que la biologie cellulaire n'était pas encore entrée dans le monde moléculaire des mécanismes biochimiques. Il y avait là un monde extraordinairement complexe de transformation membranaire dans la voie de sécrétion et pas une seule molécule n'avait encore été assignée à un rôle spécifique dans ce processus essentiel.

La première percée cruciale qui a fait entrer la voie de Palade dans l'ère moléculaire s'est faite avec la publication en 1975 par le protégé de Palade, Gunther Blobel, d'un système acellulaire qui reproduisait la traduction et la translocation du précurseur d'une protéine de sécrétion vers l'intérieur de membranes du RE isolées; deux articles dans le Journal of Cell Biology ont posé les premiers jalons pour comprendre le mécanisme du lien entre la synthèse protéique et le cheminement vectoriel des protéines sécrétoires vers ce qui était sûrement une protéine-canal hydrophile dans le RE (Blobel \& Dobberstein, 1975a, 1975b). Malgré le travail antérieur de Sabatini et Palade qui avait démontré la suite complète des événements de translocation in vitro à l'aide de microsomes isolés de tissu pancréatique, la découverte de Blobel a permis de reproduire le processus tout entier avec la mise en évidence d'un rôle essentiel pour le peptide signal $\mathrm{N}$-terminal dans le guidage de la chaîne naissante vers un site particulier de la membrane du RE.

L'hypothèse du signal et le travail magnifique qui s'ensuivit ont valu le Prix Nobel à Blobel en 1999.

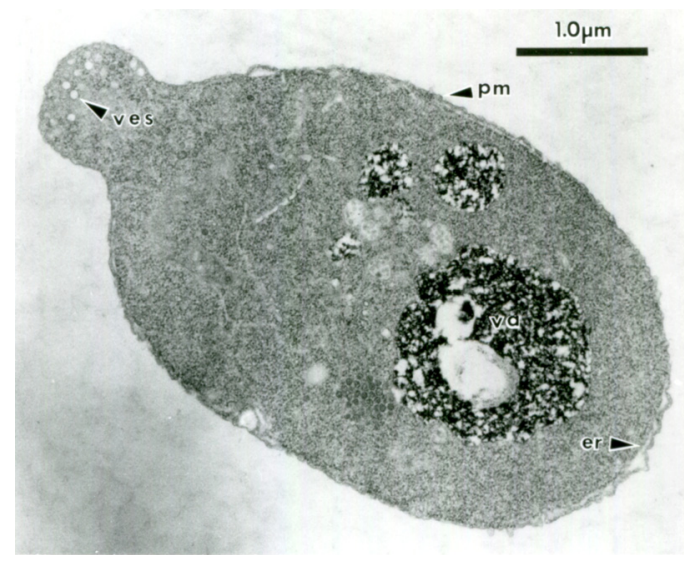

Fig. 1. Coupe ultrafine d'une cellule de levure sauvage montrant le réticulum endoplasmique (er), une vacuole (va) et des vésicules sécrétoires (ves). pm : membrane plasmique.

Singer a été très excité par la découverte de Blobel, car celle-ci étayait son point de vue selon lequel la mise en place de l'asymétrie des protéines dans la membrane devait dépendre d'un canal spécial dans le $\mathrm{RE}$ chargé de transporter les séquences protéiques hydrophiles à travers la bicouche hydrophobe. Pourtant Singer restait sceptique quant à la possibilité pour la stratégie de reconstitution biochimique d'apporter une explication approfondie du processus. Pour moi, il s'agissait précisément de la voie à explorer et pourtant mes efforts dans cette direction ont dû attendre une occasion pour prendre corps.

Je pensais de plus en plus qu'une opportunité unique se trouvait dans l'étude de l'assemblage membranaire de $S$. cerevisiae et, en lisant la littérature, je me concentrais sur ce qu'on en savait avant 1975 . Hormis le travail de Gottfried Schatz et Walter Neupert sur la biogenèse mitochondriale, il n'y avait, pour ainsi dire, rien. J'ai lu les données sur l'organisation de la surface cellulaire de la levure, particulièrement au niveau du site de division naissant : un étonnant anneau de filaments intermédiaires aboutissait à la surface cytoplasmique de la membrane du collet du bourgeon et un exceptionnel dépôt circulaire de chitine était encastré dans le polysaccharide de la paroi cellulaire (Cabib \& Bowers, 1971; Byers \& Goetsch, 1976). On voyait en microscopie électronique que les vésicules impliquées dans la sécrétion se localisaient dans le cytoplasme d'un bourgeon cellulaire jeune puis apparaissaient près du sillon de cytokinèse plus tard au cours du cycle (Byers \& Goetsch, 1974; Boer et al., 1975) (figure 1). Il paraissait raisonnable de supposer que ces vésicules étaient responsables de la sécrétion et de l'assemblage local de la membrane plasmique. Ces idées m'excitaient beaucoup plus que le travail fastidieux que je faisais sur les érythrocytes humains néonataux. 


\section{Parole et enquête libres à l'Université de Californie, Berkeley}

Alors que je quittais Stanford en direction de San Diego, j'appris qu'un poste d'Assistant Professeur s'ouvrait dans le département de biochimie de l'UC Berkeley. Bien que je n'aie pas eu encore de formation post-doctorale, je décidais de poser ma candidature à ce poste, en espérant que la faculté de Berkeley jugerait que mes résultats comme étudiant pré-doctorant attesteraient de ma motivation et de mes capacités. Heureusement pour moi, la première personne à qui on offrit le poste le déclina, et par un coup de téléphone que je n'oublierai jamais, Michael Chamberlin, un étudiant en biochimie de Stanford, formé par Paul Berg qui était alors chairman du comité de recherche de Berkeley, m'apprit la bonne nouvelle : j'avais le poste. J'étais si excité que, stupidement, j'ai accepté au téléphone sans autre négociation. Et c'est ainsi que pendant les premiers mois de ma formation postdoctorale, j'eus le luxe de planifier ma carrière future sans avoir les responsabilités de la position.

Le département de Biochimie de Berkeley était l'endroit parfait pour ce qui m'intéressait. Daniel Koshland était chairman et la faculté incluait un groupe de biochimistes classiques comme Esmond Snell, Jesse Rabinowitz, Clinton Ballou, Jack Kirsch et Howard Schachman, ainsi qu'un groupe aux intérêts plus larges en génétique et biologie moléculaire, tels que qu'Allan Wilson, Stuart Linn, Ed Penhoet, Chamberlin ainsi que Bruce et Giovanna Ames. Jeremy Thorner, un ami intime de mes années à Stanford, avait entrepris une étude de la biologie des phéromones de levure, comme membre de la faculté dans le département de bactériologie et d'immunologie de Berkeley. Ballou était un expert de la chimie des hydrates de carbone et s'intéressait particulièrement à la paroi cellulaire de la levure. Koshland, que j'avais rencontré à Stanford, et Ames étaient particulièrement attirants, parce qu'ils mariaient la génétique et la biochimie d'une manière que je trouvais compatible avec mon tempérament. Je pensais que mes futurs collègues me laisseraient toute liberté pour explorer une nouvelle direction bien différente de celles de mon travail pré-doctoral ou post-doctoral.

À la fin de mon post-doc, j'ai achevé un travail et publié un article, mais toutes mes pensées étaient dirigées vers mon futur à Berkeley. Bien sûr, je n'avais aucune expérience sur la levure et ne connaissait pratiquement rien en génétique, si bien que je prévoyais de passer trois semaines au cours de génétique de la levure donné à Cold Spring Harbor par Fred Sherman et Gerald Fink. C'était des généticiens de premier plan, qui avaient toute latitude d'inviter les élus de leur choix, parmi les personnalités de la communauté de la levure qui passaient à Cold Spring, à faire un cours et à rester un jour ou deux. Je fus heureux de rencontrer Lee Hartwell et de partager avec lui mes idées sur la manière dont les cellules de levure peuvent croître grâce au trafic vésiculaire. D'un autre côté, mes aptitudes pour disséquer des tétrades de levure n'étaient pas à la hauteur, comme il en allait pour la microscopie électronique. Je crois que j'ai eu le record du nombre minimum de tétrades disséquées jusqu'à ce que, plusieurs années après, James Rothman suive le stage.

\section{Comment étudier la sécrétion chez la levure}

Comme le moment de mon installation à Berkerley approchait, je me suis mis à travailler fiévreusement pour bâtir une proposition de grant NIH, qui inclurait un ensemble d'idées sur la manière d'étudier la sécrétion et la croissance des membranes chez la levure. Les données publiées suggéraient que la sécrétion était localisée à la partie bourgeonnante de la cellule en division mais il n'y avait pas d'outils disponibles pour étudier la localisation d'une protéine de la membrane plasmique nouvellement synthétisée. Mes idées étaient fantaisistes et, sous le projecteur, le panel des évaluateurs du NIH trouva mon expérience inadaptée (je n'avais pas de résultats préliminaires) et mes idées sans fondement. Le rejet fut humiliant et mes collègues durent se demander si leur pari sur moi était en train de s'effondrer. Ajoutant l'insulte à la blessure, le March of Dimes me refusa un contrat Basil O'Connor destiné à lancer une recherche nouvelle. Là, l'interviewer me trouva intelligent mais regretta que je n'aie pas proposé de travailler sur la division cellulaire dans le syndrome de Lesch Nyhan! Heureusement, le NSF, et des évaluations amicales de Lee Hartwell et de Susan Henry, une jeune généticienne qui étudiait la régulation des phospholipides, me sauvèrent avec un contrat princier de 35000 dollars pour deux ans. Avec ce contrat et une petite bourse interne de l'Université, un effort modeste pouvait prendre forme.

Par où commencer? À l'automne 1976, deux doctorants, Janet Scott et Chris Greer, rejoignirent mon labo. Janet était transfuge d'un autre labo et devait donc trouver un projet qui donnerait rapidement des résultats. Je sentais que, pour étudier la membrane plasmique de la levure, il serait nécessaire d'avoir un moyen propre d'éliminer la paroi cellulaire en évitant l'utilisation de la glusulase, un extrait enzymatique brut d'intestin d'escargot, qui servait à convertir les cellules en sphéroplastes. Une autre enzyme lytique sécrétée par une bactérie du sol, Oerskovia xanthineolytica, semblait intéressante pour réaliser cette purification. Janet a mis au point les conditions d'induction et d'isolement de cette enzyme que 
nous avons appelée lyticase (Scott \& Schekman, 1980). Ultérieurement, le gène bactérien a été cloné et on utilise encore la lyticase recombinante, comme enzyme pour les expériences qui exigent des membranes intactes. Chris voulait également mener un projet biochimique, je le lançais donc sur un essai de purifier l'actine de la levure, ce qui, à l'époque, semblait un choix logique pour une protéine qui pouvait être impliquée dans le trafic vésiculaire. Chris a achevé son projet mais c'est seulement des années plus tard que Peter Novick, alors post-doc chez David Botstein, a montré qu'une mutation $t s$ de l'actine retardait et délocalisait la sécrétion à une température défavorable à la croissance (Novick \& Botstein, 1985).

Avec un petit labo, un peu d'argent et du temps libre sans autres responsabilités, j'initiais deux de mes propres projets : regarder la localisation de la sécrétion avec comme centres d'intérêt la chitine, un polysaccharide dans le septum de division, et une enzyme, l'invertase, sécrétée dans la paroi cellulaire. Ma première étudiante, Vicki Brawley (à présent Vicky Chandler), m'aida à analyser un pic inattendu de la synthèse de chitine qui accompagnait l'arrêt du cycle de division cellulaire de la levure, en réponse à la phéromone de conjugaison, le facteur $\alpha$. Ce travail donna lieu à ma première publication indépendante, un papier dans PNAS qui fut critiqué, édité et présenté par Clint Ballou (Schekman \& Brawley, 1979). La notion de dépôt localisé et d'activation de la chitine-synthase de la membrane plasmique paraissait défendable, mais le sujet excitait peu d'intérêt en dehors d'une petite communauté de chercheurs travaillant sur la levure. Heureusement une percée dans l'étude de la sécrétion d'invertase renforça dans mon esprit l'importance de travailler sur un sujet d'intérêt général.

Après quelques mois, Peter Novick se joignit à mon groupe pour son travail de thèse. Peter était discret, concentré et très fort sur le plan technique. Sa formation était remarquable, il avait préparé sa licence au MIT et passé les étés comme étudiant chercheur dans le labo d'Arthur Karlin à l'Université Columbia où son père était Professeur de physique. Peter focalisa son travail sur l'invertase, une enzyme qui hydrolyse le sucrose en glucose et fructose et que les cellules de levure utilisent pour mobiliser l'hexose et permettre sa capture par transport actif à la surface cellulaire. La synthèse d'invertase est réprimée dans les cellules qui croissent sur un milieu contenant une forte teneur $(2 \%)$ en glucose et est déréprimée quand les cellules sont replacées sur un milieu pauvre en glucose $(0,1 \%)$. Peter a observé que la sécrétion d'invertase est rapide : le pool d'intermédiaires intracellulaires de la sécrétion d'invertase diminue dans les cinq minutes suivant l'addition de cycloheximide qui bloque la néosynthèse de protéines. Il a ensuite essayé des agents chimiques connus pour inhiber la sécrétion dans les cellules animales, pour voir s'ils pouvaient être utilisés sur la levure. Ma première idée avait été de trouver un moyen de bloquer la fusion des vésicules sécrétoires à la surface cellulaire pour voir si la sécrétion et la croissance de la membrane plasmique étaient toutes les deux arrêtées. Ces expériences-là ont échoué et nous avons été confrontés au problème de trouver des mutants.

Pendant cette première année, j'ai donné suite à une observation étonnante faite par Susan Henry, alors à l'École Médicale Albert Einstein; elle avait observé que la privation de nutriments, chez une levure auxotrophe pour l'inositol, conduisait à un arrêt de croissance rapide et à la mort (Henry et al., 1977). Elle avait démontré que les cellules affamées accroissent leur densité en gradient, ce qui suggérait un déséquilibre dans la biosynthèse des macromolécules et une croissance nette de la surface cellulaire (Henry et al., 1977). J'ai testé la possibilité que l'inositol soit requis pour la sécrétion et la croissance de la surface cellulaire en évaluant l'activité de l'invertase dans les cellules intactes, pour mesurer l'enzyme dans la paroi (les cellules de levure sont imperméables au sucrose et ne peuvent le transporter) et dans des sphéroplastes lysés au détergent dont on avait éliminé la paroi cellulaire, pour quantifier les intermédiaires intracellulaires dans la sécrétion. Autre impasse : je trouvai que la privation d'inositol ne bloquait pas la sécrétion.

\section{Les mutants de sécrétion}

Pendant mes années post-doctorales, j'avais gardé une boîte de fiches à idées pour des projets à poursuivre dans mon labo à Berkeley. L'une de ces nombreuses idées était de chercher des mutants de sécrétion. Nous aurions pu initier cette recherche immédiatement, mais n'étant pas généticien, je ne pensais tout simplement pas de cette manière-là. Et lorsque le travail de Novick nous conduisit inévitablement à cette stratégie, nous avons présumé qu'un blocage de la sécrétion serait létal et qu'il faudrait trouver une procédure de sélection pour repérer une mutation $t s$ rare. Mais quel pourrait être l'avantage sélectif d'une cellule moribonde, sécrétant faiblement, sur une cellule viable? Une possibilité serait de sélectionner contre des cellules capables d'absorber une substance toxique par l'intermédiaire d'une perméase de surface nouvellement synthétisée, une cellule dont l'export de cette perméase serait bloqué chez le mutant, de telle sorte que ce mutant survivrait à l'exposition à la toxine. Nous nous sommes décidés pour la sulfate perméase de levure, qui ne peut discriminer sulfate et chromate. Dans les conditions adéquates, le chromate tue les cellules qui expriment la sulfate perméase. Et, en effet, dans un crible de mutants survivant à l'exposition au 
chromate à $37{ }^{\circ} \mathrm{C}$, une température non permissive standard pour la levure, Peter a découvert une mutation ts létale qui bloquait aussi la sécrétion d'invertase. Toutefois, en reproduisant les conditions de sélection, il a constaté que le mutant mourait à $37^{\circ} \mathrm{C}$ encore plus vite que la souche sauvage en présence ou en absence de chromate. Ce n'était donc pas du tout une sélection! Nous en avons conclu que les mutations ne sont peut-être pas si rares après tout et qu'une recherche « de style Hartwell » parmi un assortiment de mutations ts au hasard pourrait faire sortir des anomalies plus spécifiques de la sécrétion.

Le mutant sec1, qui résulta de l'essai abortif de sélection, se révéla conforme à toutes les prédictions que nous avions faites. À la température permissive, $24{ }^{\circ} \mathrm{C}$, les cellules mutantes se comportaient comme des cellules sauvages pour la croissance et la sécrétion rapide d'invertase et pour une autre enzyme sécrétée facile à tester, la phosphatase acide. L'induction et l'apparition de perméase sulfate était également normale. Cependant, placées à $37^{\circ} \mathrm{C}$, les cellules mutantes sec1 arrêtaient la sécrétion d'invertase et de phosphatase acide, qui s'accumulaient à haut niveau dans les cellules moribondes, et la perméase sulfate n'apparaissait pas dans les cellules intactes. Ces blocages étaient réversibles et au retour à $25{ }^{\circ} \mathrm{C}$, l'invertase accumulée et l'acide phosphatase étaient sécrétées même en absence de nouvelle synthèse protéique (figure 2). Nous en avons donc conclu que la protéine mutante Sec1 doit être thermiquement, mais réversiblement, instable.

En mai 1978, George Palade est venu à Berkeley pour deux conférences d'une série sponsorisée par la compagnie Smith, Kline et French. C'était la première occasion que j'avais de le rencontrer personnellement et ce fut exaltant de partager avec lui ce que nous faisions pour étudier la sécrétion chez la levure. Il ne savait pas que les cellules de levure sécrètent des glycoprotéines. Les doctorants ont reçu Palade à dîner et, au cours de la conversation, Peter Novick a raconté ses résultats récents sur le mutant sec1. Palade a encouragé Peter à examiner le mutant au microscope électronique. Peu de temps après, Peter m'a appelé à mon bureau, du labo de microscopie électronique au sous-sol du bâtiment de chimie, en me pressant de venir voir les images des cellules mutantes sec1. Ces images étaient sensationnelles : les cellules débordaient de vésicules qui remplissaient le compartiment cytoplasmique entier (figure 3). Une coloration cytochimique spécifique de la phosphatase acide montrait que toutes les vésicules contenaient cette enzyme et probablement d'autres protéines sécrétées par les cellules de levure. Les cellules mutantes cultivées à $24^{\circ} \mathrm{C}$ se comportaient de la même manière que les cellules sauvages, avec un petit groupe de vésicules dans la portion bourgeonnante de la cellule. Mis à part les

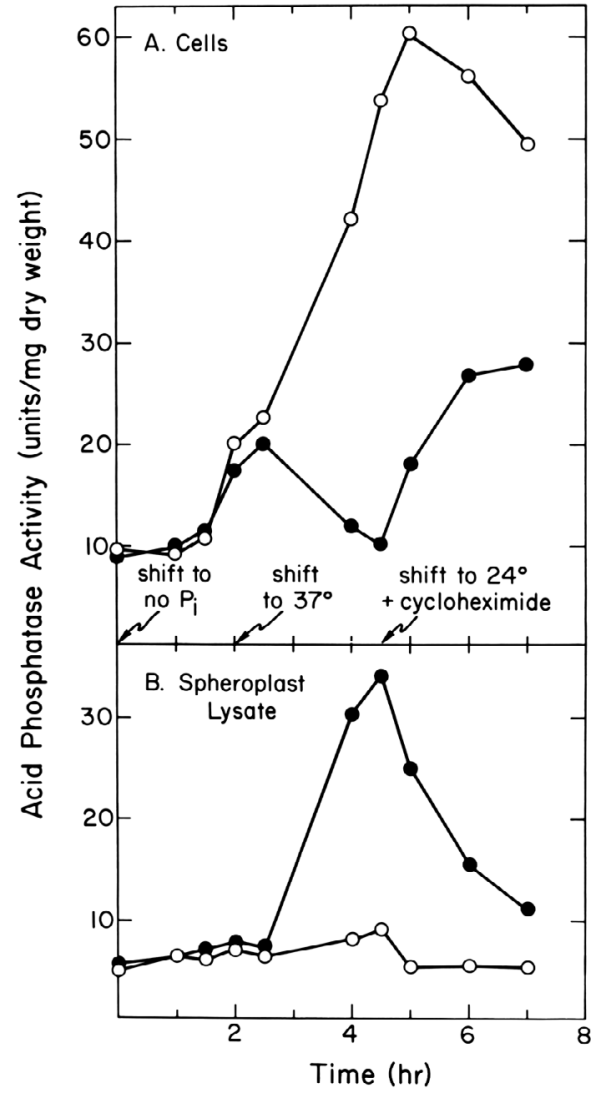

Fig. 2. Sécrétion et accumulation de phosphatase acide dans des cellules de type sauvage (cercles vides) et des cellules mutantes sec1 (cercles pleins) en A, et dans des sphéroplastes en B. Reproduit d'après Novick \& Schekman (1979).

moments où j'ai assisté à la naissance de mes enfants, rien d'autre dans ma vie ne se compare à l'excitation suscitée par ces images dans la pièce de microscopie électronique pendant l'été de 1978.

Peter et moi avons préparé un article pour PNAS, qui a été présenté par Dan Koshland (Novick \& Schekman, 1979), et nous avons continué la quête d'autres mutants de ce type, parce qu'avec cette procédure défavorable à la sélection de $\sec 1$, beaucoup d'autres gènes pouvaient certainement être trouvés sans sélection aucune. Peter a collecté au hasard 100 colonies mutantes $t s$ à l'aide d'un protocole de mutagenèse standard et a découvert un mutant de plus, sec2, qui ressemble phénotypiquement à sec1 par l'accumulation d'une population uniforme de vésicules. Deux protéines au moins sont donc impliquées dans une étape de la décharge des vésicules vers une membrane cible, peut-être la membrane plasmique. Mais il devait sûrement $\mathrm{y}$ avoir d'autres gènes de ce type et la perspective de générer des milliers de colonies $t$, à 

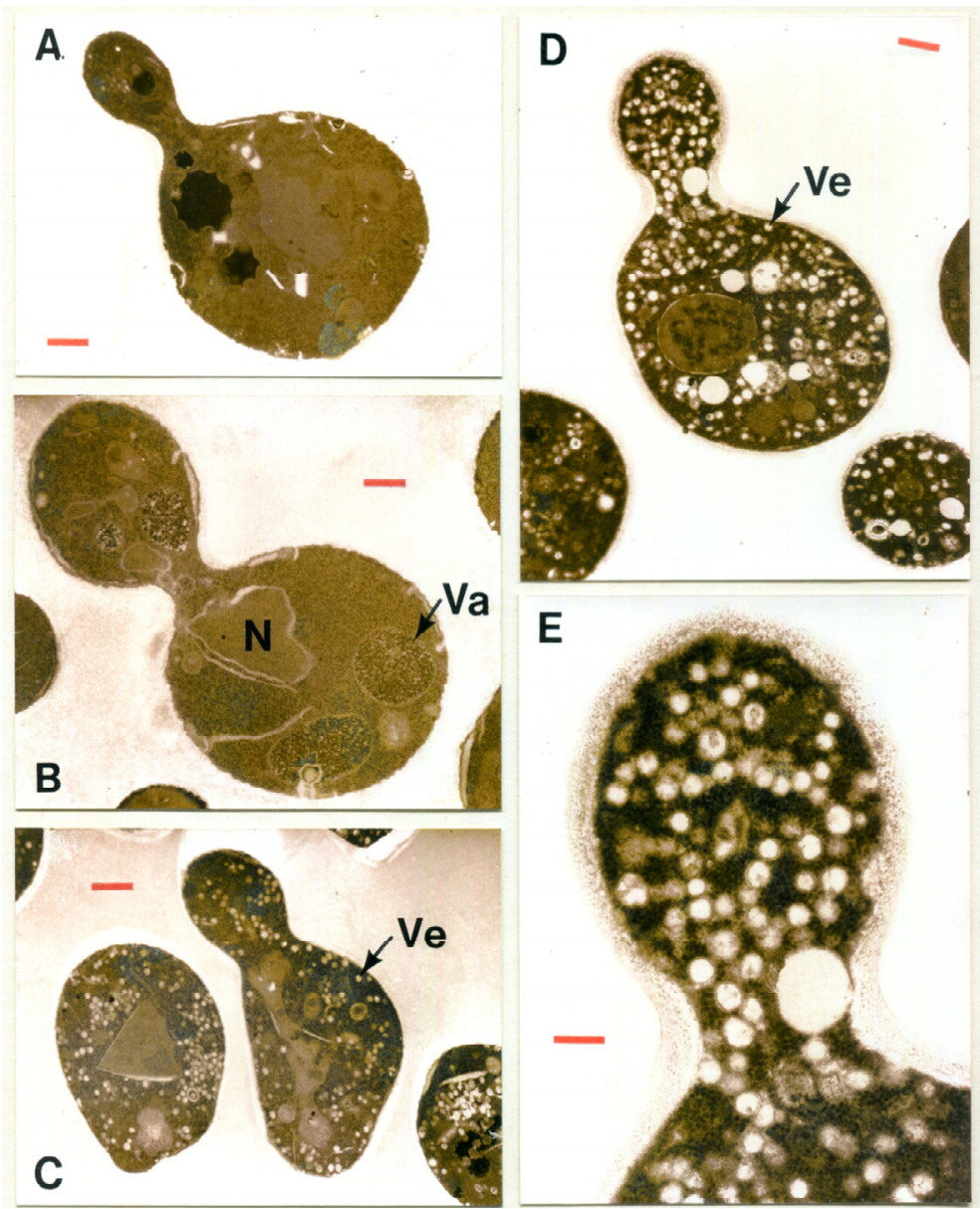

Fig. 3. Cellules sauvages (A) et cellules mutantes sec 1 à $24{ }^{\circ} \mathrm{C}(\mathrm{B})$, et à $37^{\circ} \mathrm{C}$ après $1 \mathrm{~h}(\mathrm{C})$ ou 3 heures $(\mathrm{D}, \mathrm{E})$. N : noyau; Va : vacuole; Ve : vésicule. Reproduit d'après Novick \& Schekman (1979).

une époque où la robotique d'aujourd'hui n'était pas encore développée, était plutôt décourageante.

Pour la suite de ce qui devait être une brillante série d'observations, Peter a remarqué que les mutants sec1 ne grossissaient pas, ne se divisaient pas et devenaient réfringents en contraste de phase, après une heure ou plus de réincubation à $37^{\circ} \mathrm{C}$. Ceci contrastait avec le comportement des mutants $t s$ du cycle cellulaire de Hartwell qui s'arrêtent avec une morphologie unique, caractéristique du stade du cycle bloqué, mais continuent à grandir avec des structures malformées. Peter en a déduit que les cellules défectives pour la sécrétion pouvaient continuer à produire des macromolécules mais que, parce qu'elles ne croissent pas, leur densité en gradient augmente, exactement comme je l'avais prévu pour l'auxotrophe d'inositol de Susan Henry. Peter réalisa alors une expérience magnifique pour tester sa théorie. Des cellules mutantes ont été construites avec une expression constitutive de la phosphatase acide et un aliquot a été incubé à $37^{\circ} \mathrm{C}$. Un échantillon correspondant de cellules sauvages avec un gène normalement réprimé de la phosphatase a été mélangé à 100 pour une avec les cellules mutantes; l'ensemble a été centrifugé sur un gradient de Ludox, une suspension colloïdale de silice, alors vendue comme lustrant pour les sols. Susan Henry avait utilisé la même préparation de Ludox pour séparer des cellules privées d'inositol de cellules normales. Des fractions du gradient, ensemencées sur un milieu riche, ont formé des colonies, puis ont été colorées avec un réactif histochimique spécifique de la phosphatase pour révéler la distribution des colonies à phosphatase constitutive et les colonies réprimées. On a ainsi constaté une séparation parfaite des cellules mutantes sec1 en bas du gradient et des cellules normales en haut (figure 4). Ce gradient de densité apportait le moyen que Peter recherchait pour enrichir et cribler encore beaucoup de colonies $t s$ en mutants sec additionnels.

Pendant les 18 mois suivants, Peter aidé de Charles Field, un technicien expert en génétique de la levure, répéta la mutagenèse à grande échelle avec 


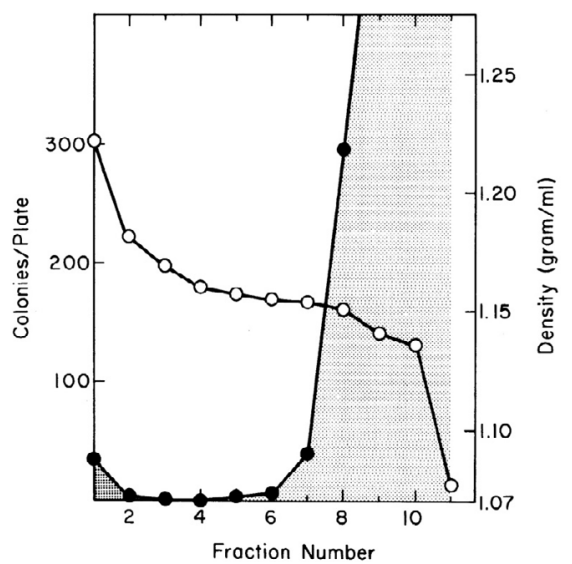

Fig. 4. Cellules sauvages (gris clair) et cellules mutantes sec 1 (gris foncé), séparées sur gradient Ludox. Colonies / Plate : nombre de colonies par boîte. Reproduit d'après Novick et al. (1980).

différents mutagènes, et rassembla une grande collection de colonies ts enrichies par gradient de densité, dont 220 étaient déficientes pour la sécrétion. Des tests de complémentation génétique révélèrent 23 gènes nouveaux parmi les mutants et la distribution des allèles indiqua la probabilité de découvrir encore d'autres gènes. L'examen au microscope électronique révéla trois catégories phénotypiques distinctes de perturbation des organites : des mutations dans 10 gènes, comme sec1 et sec2, provoquaient l'accumulation des vésicules sécrétoires, des mutations dans 9 autres gènes engendraient l'accumulation et la distorsion des membranes du RE, deux autres déclenchaient la prolifération d'un organite en forme de toroïde, que Novick appela le « corps de Berkeley ». Notre souci était que les mutations sec auraient pu ne pas toucher des composants de la machinerie de sécrétion, mais seulement des protéinescargo défectives interférant avec la sécrétion. Pourtant, les tests de complémentation simples utilisés pour identifier les gènes montrèrent que tous les allèles étaient génétiquement récessifs, et par conséquent n'étaient pas, en toute probabilité, des inhibiteurs dominants du processus. Novick et Field ont effectué une caractérisation morphologique et physiologique des allèles sélectionnés pour chacun des 23 gènes et nous avons préparé un article très complet pour le journal Cell, relativement nouveau, qui grâce à la personnalité forte de l'éditeur, Benjamin Lewin, était en train de modifier la façon dont la science était évaluée et promue (Novick et al., 1980).

L'année suivante, Novick et Susan Ferro, qui devint ensuite Susan Ferro-Novick (le premier de nombreux mariages à l'intérieur de mon labo), firent équipe pour mettre en œuvre un test classique d'épistasie génétique pour établir l'ordre selon lequel les gènes sec

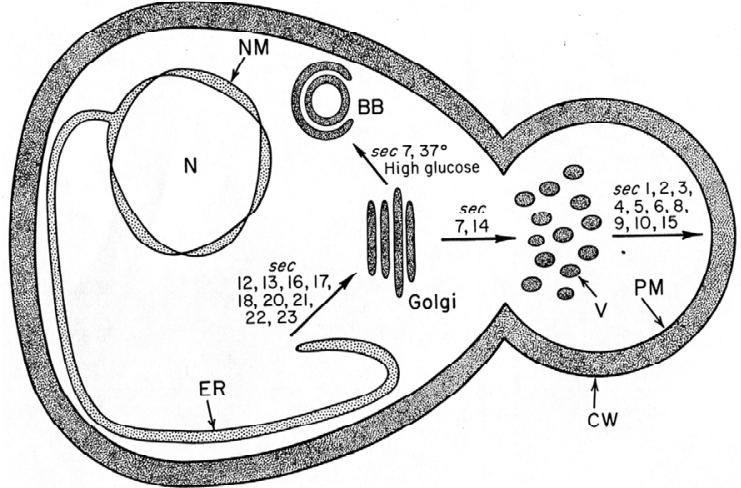

Fig. 5. Voies sécrétoires de la levure (vers 1981). High glucose : taux de glucose élevé. BB : Berkeley body. ER : réticulum endoplasmique. $\mathrm{CW}$ : paroi cellulaire (cell wall) $\mathrm{N}$ : noyau. NM : membrane nucléaire. PM : membrane plasmique. Reproduit d'après Novick et al. (1981).

exercent leur fonction. Au cours de ce travail, Peter a trouvé que l'un des mutants de sec7 qui accumule les bizarres « corps de Berkeley » semble posséder un constituant équivalent à celui de l'appareil de Golgi des cellules de mammifères. Tout à fait par hasard, il a trouvé que cette structure bloquait la sécrétion de manière irréversible, sauf si les cellules sont incubées dans un milieu pauvre en glucose, auquel cas les cellules mutantes présentent une structure de Golgi classique avec de multiples citernes (Novick et al., 1982). Quelques années plus tard, Chris Kaiser, un post-doc talentueux très expérimenté en génétique de la levure, a revisité les gènes $S E C$ qui gouvernent le trafic à un stade précoce de la voie de sécrétion et a découvert une catégorie distincte de vésicules plus petites qui assure le passage entre le RE et le complexe de Golgi (Kaiser \& Schekman, 1990). Il a distingué un groupe de gènes $S E C$ qui gouverne la formation des vésicules et un autre groupe requis pour leur disparition, probablement par un processus de fusion au complexe de Golgi. Il a montré une chose importante : les deux groupes de gènes montrent des interactions génétiques extensives, les mutations dans un groupe exacerbant le phénotype mutant d'autres membres du groupe, alors que ces interactions ne se produisent pas entre les deux groupes. Ce comportement, désigné comme une «interaction synthétique létale», suggérait que les membres de chaque groupe fonctionnent peut-être par interaction physique les uns avec les autres. Ces résultats conduisaient à une image de la voie de sécrétion chez la levure essentiellement semblable à celle découverte par Palade dans les cellules de mammifères, avec en prime le point crucial que chaque étape dans la chaîne complexe d'évènements était maintenant définie par des gènes, donc par des protéines, qui certainement allaient éclairer les mécanismes moléculaires de cette voie (figures 5 et 6 ). 




Fig. 6. Voie du trafic des vésicules golgiennes (vers 1990). Reproduit de Kaiser \& Schekmann (1990).

Deux autres études ajoutèrent ensuite des détails moléculaires à l'image de la voie de sécrétion chez la levure, qui émergeait. Brent Esmon, un étudiant du labo, utilisa un colorant histochimique de l'invertase sur des échantillons de lysats cellulaires soumis à une électrophorèse sur un gel natif de polyacrylamide. Il découvrit ainsi que les mutants défectifs pour le transport de protéines à partir du RE accumulent des formes individualisées d'invertase glycosylée, distinctes de l'invertase qui voyage vers le compartiment golgien et les vésicules sécrétoires. À l'aide d'anticorps qui révèlent les épitopes glucidiques de la « chaîne externe » des glycoprotéines de levure, Brent a constaté que la division du travail entre le RE et le complexe de Golgi chez la levure, quant à la maturation des Nglycanes, est à peu près la même que dans les cellules de mammifères (Esmon et al., 1981). Tom Stevens, un stagiaire post-doctorant, a étudié le parcours d'une protéine vers la vacuole de la levure et a trouvé qu'elle est détournée du complexe de Golgi, tout à fait comme dans le trafic des protéines lysosomales dans les cellules de mammifères (Stevens et al., 1982). Stevens et un autre post-doc, Scott Emr, ont importé cette partie de la voie de sécrétion dans leurs propres labos (Université d'Orégon et Cal Tech respectivement) pour développer des moyens de sélection génétique puissants afin de découvrir les gènes qui régissent cette séquence du tri de la voie sécrétoire. Les gènes VPS continuent de mettre en lumière le processus de tri du complexe de Golgi vers l'endosome et vers la vacuole ou vers le lysosome dans tous les organismes nucléés.

Notre découverte, selon laquelle les voies sécrétoires de la levure et des mammifères sont dans l'ensemble conservées, étant acquise, l'industrie biotech se mit rapidement à exploiter les possibilités de fermentation des cultures de levure pour obtenir industriellement des quantités commerciales de protéines humaines d'intérêt. Chiron, près de Berkeley dans la baie de San Francisco, a été la première à réussir. L'expression recombinante de l'antigène de surface de l'hépatite B chez la levure permit la production de particules membranaires semblables à celles du virus, qui se sont révélées hautement immunogènes, et qui ont été commercialisées comme un vaccin très efficace contre l'hépatite, seule source aujourd'hui de ce produit (Valenzuela et al., 1982). L'hépatite B étant la cause majeure du cancer primitif du foie, l'introduction réussie de cette préparation issue de la voie de sécrétion de la levure pourrait, si elle était diffusée très largement, réduire de manière dramatique l'incidence du cancer $\mathrm{du}$ foie. Effectivement ce produit commercial est considéré comme le premier vaccin anti-cancer. Chiron a ensuite développé l'expression et la sécrétion de l'insuline humaine au niveau industriel chez la levure et cette molécule, mise sur le marché aujourd'hui par Novo Nordisk, est à l'origine d'un tiers de l'approvisionnement en insuline recombinante à l'échelle mondiale.

Je n'ai jamais breveté aucune de nos découvertes, ni pensé à œuvrer pour des applications commerciales dans mon laboratoire, parce que j'étais complètement absorbé dans la poursuite du savoir fondamental. Il n'empêche, comme consultant pour Chiron, j'ai bénéficié d'avantages financiers et ai été extrêmement gratifié de voir notre travail appliqué à des buts pratiques d'une telle importance. Je pense que le travail de découverte de médicaments et l'application pratique doivent être laissés au secteur privé; les scientifiques universitaires devraient se concentrer sur les découvertes fondamentales.

\section{Gènes importants découverts par d'autres moyens}

Bien que l'assortiment initial de gènes $S E C$ ait révélé les grandes lignes de la voie de sécrétion, il est devenu apparent que des éléments clés du processus n'étaient pas reflétés dans les mutants de Novick. Nous avions espéré trouver des mutations qui bloqueraient l'insertion des polypeptides sécrétoires dans la lumière du RE et définiraient ainsi les gènes qui codent pour le canal de translocation prédit par le travail classique de Palade, Sabatini et Blobel. Selon la prédiction clé de départ, les mutations dans ce canal hypothétique provoqueraient l'accumulation de polypeptides précurseurs non glycosylés dans le cytoplasme. Aucun défaut de ce type n'a été trouvé dans la série initiale de mutations sec. Susan Ferro a conduit une recherche plus approfondie pour ces mutants à l'aide de la technique du gradient de densité et en a trouvé deux qui accumulaient des formes non glycosylées d'invertase (Ferro-Novick et al., 1984). Cependant, après examen plus détaillé, ces mutations identifiaient des gènes impliqués dans la biosynthèse de glycanes au niveau des protéines de sécrétion plutôt 
que des vrais catalyseurs de translocation (Kepes \& Schekman, 1988; Bernstein et al., 1989). Il fallait clairement, une approche différente, plus directe.

Les analyses chez E. coli et chez la levure avaient montré que le peptide signal N-terminal est nécessaire et suffisant pour la translocation d'une protéine de sécrétion, au travers de la membrane cytoplasmique pour E. coli ou d'une membrane du RE dans la levure (Silhavy et al., 1976; Emr et al., 1984). L'expression recombinante d'une protéine chimérique construite par la fusion d'une séquence codant le peptide signal et du gène $\beta$-galactosidase d'E. coli, qui code une enzyme cytoplasmique soluble, a pour conséquence la translocation membranaire de la protéine hybride. Beckwith et ses collaborateurs ont trouvé que l'expression d'une telle protéine hybride chez E. coli apportait un phénotype de croissance sélectionnable, qu'ils utilisèrent pour isoler des mutations sec défectives pour la translocation, définissant ainsi les nouvelles protéines cytoplasmiques SecA et SecB (Oliver \& Beckwith, 1981). À l'aide d'autres approches génétiques, Silhavy, Ito et leurs collègues ont identifié un gène codant pour une protéine membranaire, PrlA/SecY, candidate pour le canal de translocation bactérien (Emr \& Silhavy, 1980; Shiba et al., 1984).

Ray Deshaies, un étudiant particulièrement créatif et doté de confiance en soi, a rejoint le labo au milieu des années 1980 et, après un essai initial sur les mutants sec existants, a décidé de revisiter le problème de la translocation. Au cours de trois essais brillants mais tout à fait indépendants, il a réussi à définir un certain nombre de gènes requis dans le processus de translocation. Ray a pensé que si un peptide signal était fixé à une enzyme nécessaire à la production d'un nutriment essentiel, l'enzyme serait séquestrée dans le $\mathrm{RE}$, isolée de tout contact avec son substrat. Dans cette situation, les cellules croîtraient sur le nutriment mais pas sur son substrat, à moins qu'une mutation ne soit introduite qui bloquerait la translocation de la protéine hybride dans le RE. Bien sûr, une mutation dans une protéine essentielle de canal tuerait probablement la cellule, si bien que la quête était celle de mutations qui paralyseraient mais ne détruiraient pas la protéine nécessaire au processus d'assemblage. Les mutations létales sensibles à la température exercent souvent un effet partiel à la température permissive, la recherche était donc celle de mutants qui poussent à $30{ }^{\circ} \mathrm{C}$ sur le substrat - dans notre cas l'histidinol, substrat de l'enzyme histidinol-déshydrogénase, dernière étape dans la biosynthèse de l'histidine mais qui n'arrivent pas à former des colonies à $37^{\circ} \mathrm{C}$ sur un substrat riche. Le premier mutant de Ray fut appelé sec61 et, en utilisant la même technique de sélection, cinq autres gènes furent ensuite identifiés, codant pour des fonctions additionnelles essentielles pour la translocation, y compris pour d'autres sousunités du complexe canalaire et une sous-unité de la particule de reconnaissance du signal (SRP) (Deshaies \& Schekman, 1987; Rothblatt et al., 1989). Le clonage ultérieur de ces gènes a révélé que Sec61 est homologue au gène $\operatorname{PrlA} / \operatorname{Secy} Y$ de E. coli (Stirling et al., 1992). Des gènes comparables sont trouvés chez les mammifères et l'analyse biochimique a fait la preuve que la protéine Sec61 constitue le cœur de la protéinecanal à travers laquelle les protéines sécrétoires et membranaires passent pendant l'assemblage dans le RE (Nakano et al., 1988; Gorlich et al., 1992).

Deshaies aborda aussi la question de savoir si certaines protéines de sécrétion peuvent être transloquées après la traduction chez la levure. En contraste avec la règle classique de translocation co-traductionnelle découverte par Blobel, Peter Walter, un protégé de Blobel, découvrit qu'au moins un substrat, le précurseur du facteur $\alpha$, la phéromone de conjugaison de la levure, pouvait traverser la membrane du RE après l'achèvement de la traduction (Gorlich \& Rapoport, 1993). On supposait que quelque chose d'extrinsèque ou d'intrinsèque à ce précurseur le maintenait sous une forme qui pouvait facilement se déplier pendant la translocation.

Lisant une revue notoire de Hugh Pelham sur le rôle possible de la famille des protéines heat shock hsp70 dans la dispersion des agrégats de protéines (Hansen et al., 1986), Ray a imaginé que hsp70 pourrait aussi servir à retenir des formes partiellement dépliées de substrats post-traductionnels comme le précurseur du facteur $\alpha$. Heureusement, nous avions la possibilité de tester cela in vivo parce que Margaret Werner-Washburn et Elizabeth Craig venaient de construire une souche de levure à laquelle manquaient trois des protéines majeures de la classe hsp70 et était ajoutée une mutation $t s$ dans le quatrième gène restant, de telle sorte que le quadruple mutant était ts létal. Ray établit rapidement que ce mutant accumulait le précurseur du facteur $\alpha$ non transloqué et, en prime, il montra que la sous-unité $\beta$ de la $\mathrm{F}_{1}$-ATPase mitochondriale, également transloquée dans cet organite après traduction, s'accumulait dans le cytoplasme. Ray et, indépendamment, Chirico et Blobel montrèrent que l'exigence en hsp70 pouvait être reproduite dans la réaction acellulaire qui mime la translocation du précurseur du facteur $\alpha$ dans les membranes isolées du RE de levure (Pelham, 1986; Chirico et al., 1988; Deshaies et al., 1988).

Troisième exemple de l'esprit créatif de Deshaies, il résolut un problème qui avait tourmenté un post-doc, Peter Bohni. Celui-ci s'était battu pendant deux ans pour obtenir une mutation dans la signal-peptidase de la levure, l'enzyme dont Blobel avait démontré qu'elle scinde le signal d'un polypeptide sécrétoire alors qu'il émerge du côté luminal du RE. Ni l'enzyme ni le gène 
pour la peptidase n'avait été obtenus; il était donc intéressant de tester la fonction de la protéine, qui, à ce moment-là, restait candidate comme sous-unité du canal de translocation. Nous savions qu'une mutation au site de clivage du peptide signal de l'invertase de la levure retardait la sécrétion de l'enzyme active, qui s'accumule alors sous forme de précurseur dans le RE (Schauer et al., 1985). Des tentatives pour obtenir une sélection de mutations dans la peptidase, basée sur ce retard de sécrétion, s'avérèrent infructueuses.

Ray suggéra que des protéines-cargo non clivées pourraient être retardées plus fortement que d'autres et qu'une peptidase mutante pourrait se trouver dans notre collection originelle de mutants sec; cette mutation aurait présenté la caractéristique inhabituelle de bloquer un sous-ensemble de protéines-cargo. Au cours de ses dernières expériences comme doctorant, Peter Novick avait développé une procédure de marquage chimique de la surface cellulaire, afin d'établir la liste complète des protéines de fret majeures et comment leur apparition à la surface cellulaire est affectée dans les cellules mutantes sec incubées à $37^{\circ} \mathrm{C}$ (Novick \& Schekman, 1983). Curieusement, un mutant de la collection originelle, sec11, présentait une anomalie, certaines protéines-cargo étant bloquées et d'autres moins. Avec cette idée, Bohni s'attacha tout de suite au mutant sec11 et trouva qu'il accumulait de l'invertase non clivée à température restrictive (Böhni et al., 1988). Le gène $S E C 11$ fut cloné et reconnu comme le prototype de toutes les signal-peptidases eukaryotiques (Greenberg et al., 1989).

\section{Cloner des gènes pour compléter l'analyse fonctionnelle des protéines Sec}

Avec l'avènement du clonage des gènes de levure par complémentation, introduit par Hinnen et Fink en 1978, nous avions la perspective immédiate d'une description moléculaire des gènes $S E C$ et de leur alignement éventuel avec ceux qui ont des fonctions comparables chez les métazoaires simples et peut-être même les mammifères. J'ai résisté à la tentation de me lancer dans cette direction, car il semblait peu vraisemblable que ces gènes $S E C$ puissent ressembler à quelque chose de connu à cette époque. Après tout, le séquençage de l'ADN était encore dans son enfance et les bases de données du génome n'existaient pas. Presqu'au début de notre caractérisation des mutants $s e c$, mon but était de développer une réaction acellulaire imitant la fonction des protéines Sec. La plupart des étudiants et des stagiaires qui rejoignaient mon labo résistaient à mes prières ou n'entreprenaient que des tentatives peu enthousiastes. Un essai initial dans cette direction livra un signal faible qui ne semblait pas devoir être utile (Haselbeck \& Schekman, 1986).
Pourtant, quelques miles plus loin dans son nouveau labo de Stanford, Jim Rothman avait réussi à obtenir une réaction qui semblait mesurer une portion significative du trafic golgien reconstitué dans un lysat de cellules de mammifères (Fries \& Rothman, 1980). Mes propres efforts restaient en attente jusqu'à ce que je trouve un étudiant courageux pour endosser le défi.

$S E C 53$ fut le premier gène $S E C$ cloné, dont la fonction biochimique fut identifiée. Bien que sec53 ait été isolé et caractérisé au départ comme un mutant de translocation défectif, la séquence du gène prédisait une protéine soluble (Bernstein et al., 1985), qui après une étude plus fine, se révéla être l'enzyme phospho-manno-mutase impliquée dans la production de GDP-mannose, le précurseur des N- et O-glycanes de la levure (Kepes \& Schekman, 1988). D'autres gènes $S E C$ ont été clonés, mais à part la prédiction que $S E C 12$ codait pour une protéine membranaire du RE et que $S E C 18$ codait pour une protéine cytoplasmique soluble, aucun rôle biochimique fonctionnel ne pouvait être déduit des séquences (Bernstein et al., 1985 ; Eakle et al., 1988).

La première vraie percée en ce qui concerne le trafic vésiculaire advint en 1987 lorsque Novick, maintenant dans son propre labo à Yale, a cloné et séquencé $S E C 4$, puis montré qu'il codait pour une petite protéine de la famille RAS liant le GTP (Salminen \& Novick, 1987). Que Novick s'intéresse à $S E C 4$ n'était pas un accident. Nous nous étions mis d'accord pour qu'il prenne en charge le groupe des mutants sec qui se bloquent tardivement dans la voie de sécrétion et accumulent des vésicules matures. Salminen et Novick ont découvert que la surexpression de $S E C 4$ supprimait le défaut de croissance de plusieurs membres du groupe des mutants sec à effet tardif, et que les doubles mutants construits entre les membres de cette classe présentaient une forme synthétique létale d'interaction génétique. Comme les génomes d'autres organismes étaient séquencés, il devint évident que $S E C_{4}$ était le prototype de ce qu'on appelle maintenant les protéines Rab, dont chacune définit une destination unique pour la fusion des vésicules à une membrane cible. Continuant le parcours brillant initié dès le début de ses études doctorales, Novick a construit un corpus substantiel de travaux hautement originaux qui révèlent les mécanismes détaillés associés à la production, la migration et la fusion des vésicules de transport à la surface de la cellule de levure. Étant donné la conservation fondamentale des séquences du gène $S E C$, il n'est pas surprenant que les interprétations de Novick soient valables pour tous les évènements comparables de ciblage/fusion de vésicules chez les métazoaires et les mammifères. Effectivement $S E C 1$ a été reconnu comme apparenté au gène unc-18 isolé dans la collection originelle des mutants incoordonnés de $C$. elegans assemblée par Sydney Brenner (Brenner, 1974; 
Gengyo-Ando et al., 1993). Et l'on sait que la protéine Sec1 joue un rôle universel dans le contrôle de l'effet de la protéine SNARE sur la fusion des vésicules.

Le travail pionnier de Jim Rothman pour purifier les protéines nécessaires à la fusion des vésicules a révélé l'ATPase soluble, le NSF (NEM-Sensitive Factor), qui, au clonage, s'est montré étonnement semblable à la protéine de levure Sec18, dont le gène avait été cloné par Scott Emr dans son propre labo à Cal Tech (Eakle et al., 1988; Wilson et al., 1989). À peu près au même moment, Chris Kaiser dans mon labo a détecté un intermédiaire vésiculaire entre le $\mathrm{RE}$ et le Golgi, dont la disparition par fusion requiert les gènes interactifs SEC18, SEC17 et SEC22 (Kaiser \& Schekman, 1990). Dans un article écrit en collaboration, nos labos ont montré que $S E C 17$ code pour l'équivalent chez la levure de SNAP- $\alpha$, une protéine que le labo de Rothman avait identifiée comme le facteur requis par NSF pour se lier à un site de membrane, et définie plus tard comme la protéine SNARE (Griff et al., 1992). Un travail ultérieur a montré que SEC22 code pour une protéine SNARE de levure homologue. Ces résultats révélaient que les deux labos travaillaient sur le même problème et établissaient un lien convaincant entre les mécanismes de ciblage/fusion vésiculaires chez la levure et dans les cellules de mammifères.

Le mécanisme de bourgeonnement des vésicules de sécrétion devenait alors accessible à l'analyse moléculaire. Palade avait vu des «coated vesicles» au site de sortie du RE dans des coupes de pancréas exocrine et l'idée était que le mécanisme du bourgeonnement impliquerait un revêtement semblable au classique manteau de clathrine; celui-ci avait été visualisé la première fois comme un puits recouvert engagé dans l'internalisation des protéines du vitellus dans les oocytes d'insectes, puis caractérisé au niveau moléculaire par Barbara Pearse sur des vésicules issues de cerveau bovin (Roth \& Porter, 1964; Pearse, 1976). Rothman avait des données suggérant le rôle de la clathrine dans le transport de la protéine $\mathrm{G}$ du virus de la stomatite vésiculaire à partir du RE dans des cellules de mammifères cultivées (Rothman \& Fine, 1980). Par conséquent, la clathrine ou un manteau de protéines similaires étaient candidats comme produits d'un ou d'autres gènes $S E C$ requis pour le trafic à partir du RE.

Greg Payne décida de sonder directement le rôle de la clathrine, en clonant le gène de la chaîne lourde et en caractérisant le phénotype du knock out de la clathrine chez la levure. Etant donné le rôle attendu pour la clathrine dans le trafic vésiculaire, nous supposions que, comme les gènes $S E C$, celui de la clathrine serait essentiel à la viabilité cellulaire. Pourtant, après élimination de la chaîne lourde dans une souche diploïde, Greg a eu un choc en voyant dans chaque tétrade deux spores disloquées qui croissaient après un temps de retard de plusieurs jours. Les cellules sans clathrine étaient souffreteuses mais continuaient à sécréter même si le gène était inactivé sur différents supports génétiques (Payne \& Schekman, 1985). Lemmon et Jones décrivirent une souche dans laquelle la chaîne lourde était essentielle, mais il semble maintenant probable que cette souche portait une mutation additionnelle qui exerçait un effet létal global en l'absence de clathrine (Lemmon \& Jones, 1987). Une analyse plus poussée montra que la clathrine était nécessaire pour le tri/rétention corrects d'une peptidase dibasique localisée dans le Golgi, essentielle pour la maturation protéolytique du précurseur du facteur $\alpha$ (Payne \& Schekman, 1989). Ces résultats s'accordaient bien avec la suggestion de Lelio Orci que les manteaux de clathrine interviennent dans la récupération de la protéase qui traite la proinsuline des granules en voie de condensation dans les cellules $\beta$ du pancréas (Orci et al., 1987). La recherche sur un rôle du manteau dans le mécanisme de la formation des vésicules de transport a donc continué.

\section{Une réaction de transport vésiculaire acellulaire chez la levure}

Je savais que le potentiel de la collection de mutants sec ne se déploierait complètement qu'après la mise au point d'une réaction in vitro récapitulant au moins une partie de la voie de sécrétion en l'absence de cellules. Finalement, en 1985, j'ai recruté un étudiant brillant et créatif, David Baker, qui partageait mes vues et avait le talent de réussir ce qu'il entreprenait. Jusque là nous avions utilisé l'accumulation de précurseurs de glycoprotéines, dans les cellules mutantes sec bloquées à $37{ }^{\circ} \mathrm{C}$, pour servir de substrat à des réactions in vitro.

Les glycoprotéines immatures sont modifiées en passant à travers le complexe de Golgi par des ajouts de chaînes de glycanes extérieures, lorsque les cellules sont replacées à température permissive; nous avions présumé qu'il en serait de même in vitro. Cette supposition fut démentie. La première indication d'un problème vint avec l'évaluation de la phospho-manno-mutase du mutant sec53, qui se révéla inactive même dans les lysats de cellules cultivées à température permissive (Kepes \& Schekman, 1988). Si l'accumulation des substrats dans le RE n'était pas bloquée, le test du trafic devrait reposer sur un niveau faible de glycoprotéines immatures, radiomarquées pendant un temps bref lors de la biosynthèse. Rothman avait réussi avec exactement cette stratégie (Fries \& Rothman, 1980), mais le temps de transit des glycoprotéines chez la levure est beaucoup plus rapide que dans les cellules de mammifères. 
David eut une nouvelle idée. Le labo de Peter Walter (ainsi que ceux de David Meyer et de Blobel) avait reconstitué la translocation du précurseur du facteur $\alpha$ radiomarqué dans des membranes de RE préparées par dislocation mécanique de sphéroplastes de levure (Hansen et al., 1986). Le produit de cette incubation était une molécule à cœur N-glycosylé qui migrait à une position individualisée lors d'une séparation sur SDS-PAGE. David avait deviné que des membranes préparées par une lyse moins brutale, en gros un processus de congélation-réchauffement rapide de sphéroplastes de levure, pourraient garder une organisation membranaire suffisante pour permettre le trafic vésiculaire du précurseur d'un facteur $\alpha$ synthétique dont le glycane central était modifié. Quelques semaines après avoir commencé, David a observé une dispersion hétérogène de formes du précurseur radioactif à mobilité électrophorétique faible, qui - c'est important - était précipitées par des anticorps dirigés contre les épitopes mannose ajoutés aux N-glycanes dans le complexe de Golgi de la levure. La réaction exigeait du cytosol, de l'ATP et une incubation à température physiologique. Les résultats étaient très prometteurs et le test se prêtait à la quantification et à la répétition avec de nombreux échantillons.

Le test crucial de la réaction de Baker était d'examiner dans la réaction acellulaire l'effet d'un mutant $s e c$ à ER bloqué. Linda Hicke, une étudiante ambitieuse et techniquement douée, avait cloné SEC23, l'un des quatre gènes que Kaiser avait prouvé interagir dans la formation des vésicules de transport dérivées du RE. Elle a collaboré avec Baker pour reproduire la réaction de transport du précurseur du facteur $\alpha$ dans des incubations distinctes, contenant des membranes de cellules sauvages $(w t)$ mélangées avec des fractions cytosoliques sauvages, mutantes et de cellules mutantes complémentées avec le gène sauvage. Les résultats furent formidables avec un défaut $t s$ évident du transport, lorsqu'une copie sauvage de Sec23p était apportée avec la fraction cytosolique mutante (Baker et al., 1988) (figure 7). De manière stupéfiante, Susan Ferro-Novick et son étudiante Hannele Ruohola ont développé sensiblement la même méthodologie et obtenu les mêmes résultats dans leur laboratoire à Yale (Ruohola et al., 1988).

Les résultats de Baker et de Hicke correspondaient précisément à ce dont j'avais rêvé et le modèle expérimental était inspiré par ma propre recherche de thèse, au cours de laquelle j'avais utilisé la complémentation entre des lysats mutants comme test pour purifier des enzymes fonctionnels de réplication de l'ADN (Schekman et al., 1972).

Avec son test, Linda était capable de purifier le recombinant Sec23p surexprimé et de montrer ensuite qu'il copurifiait avec une autre protéine qui n'était

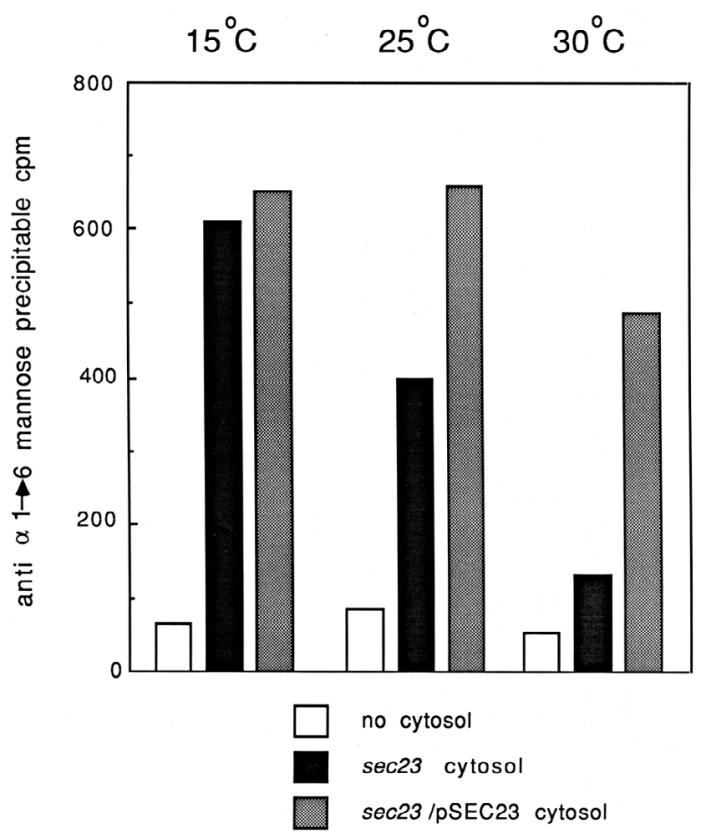

Fig. 7. Transport sensible à la température du précurseur du facteur $\alpha$. Le précurseur du Golgi, modifié par le glycane, incubé à $15{ }^{\circ} \mathrm{C}, 25^{\circ} \mathrm{C}$ et $30^{\circ} \mathrm{C}$, en présence de membranes sans cytosol (colonnes blanches), en présence de cytosol mutant sec 23 (colonnes noires), ou en présence de cytosol de mutant sec 23 complémenté avec SEC 23.

pas représentée dans notre collection originelle de mutants, mais qui s'avéra codée par un autre gène essentiel, que nous avons appelé SEC 24 (Hicke et al., 1992).

En lui-même, l'hétérodimère purifié du Sec23/24p fonctionnel n'offrait pas d'indice concernant son rôle dans le bourgeonnement des vésicules du RE. Pour cela nous avions besoin des formes purifiées des autres composants cytosoliques nécessaires au bourgeonnement $\mathrm{du}$ précurseur du facteur $\alpha$. Le facteur suivant arriva par un circuit détourné. Akihiko Nakano, le premier d'une série de post-docs japonais remarquables, avait cloné la protéine membranaire Sec12 du RE. Nous savions par le travail génétique de Kaiser que celle-ci était intimement liée à un groupe de protéines Sec solubles impliquées dans le bourgeonnement vésiculaire (Nakano et al., 1988; Kaiser \& Schekman, 1990). Nous avions dans notre collection un jeu de gènes clonés par surexpression/suppression de la mutation sec12. Un clone supprimait la croissance ts de sec12, même quand le nombre de copies était seulement double de la normale. Aki a emporté ce gène dans son labo au Japon et trouvé qu'il codait pour une autre petite protéine liant le GTP, mais d'une classe distincte par rapport à $S E C_{4}$. Ce gène, qu'il nomma $S A R 1$, se révéla également essentiel pour la sécrétion (Nakano \& Muramatsu, 1989). Christophe 
d'Enfert, un post-doc de Paris, a ensuite montré que les membranes isolées à partir d'une souche qui surexprimait SEC12 étaient défectives dans la réaction de transport, sauf si le cytosol contenait du SAR1p surexprimé (d'Enfert et al., 1991). C'est devenu le test pour purifier le SAR1 fonctionnel, dont nous avions vu qu'il pouvait aussi être isolé par expression recombinante dans E. coli (Barlowe et al., 1993).

$\mathrm{Au}$ fur et à mesure que nous alignions les protéines requises pour le bourgeonnement, il devint évident que les conditions requises pour la réaction de transport complète étaient très complexes et il a semblé raisonnable de mettre au point un essai plus simple en se concentrant seulement sur la formation des vésicules. Michael Rexach rejoignit le labo comme prédoctorant, apportant des capacités considérables et une détermination opiniâtre. À l'aide d'une simple technique de centrifugation différentielle, Michael a observé que les membranes du RE restaient intactes pendant toute la durée de l'incubation acellulaire, ce que mesurait la sédimentation rapide des protéines marqueuses du RE. Par contre, il a découvert qu'au fur et à mesure de l'incubation une partie substantielle du précurseur à cœur glycosylé du facteur $\alpha$, initialement contenu dans de grandes citernes du $\mathrm{RE}$, était transférée dans une catégorie de vésicules à sédimentation lente, qui n'avait pas d'activité de translocation ni d'autres marqueurs spécifiques de membranes du RE ou de la lumière. Il est à remarquer que la formation de cette catégorie de vésicules était bloquée dans les mutants que Kaiser avait montré comme défectifs pour la production de vésicules intermédiaires in vivo (sec12 et sec23), mais ne l'était pas dans les mutants bloqués à un stade ultérieur (sec 18) (Rexach \& Schekman, 1991). Cette fois-ci encore, des résultats similaires étaient obtenus dans le laboratoire de Ferro et Novick (Groesch et al., 1990). Le travail de Rexach nous apportait l'outil essentiel dont nous avions besoin pour achever la purification et l'analyse fonctionnelle des protéines requises par le bourgeonnement vésiculaire à partir du RE.

Deux autres gènes nécessaires à la formation des vésicules du RE restaient à identifier fonctionnellement : SEC13 et SEC16. Dans son laboratoire au MIT, Kaiser a cloné et caractérisé SEC16 et constaté que ce gène code pour une protéine de membrane périphérique de $240 \mathrm{KD}$, difficilement libérée dans le cytosol (Espenshade et al., 1995). Nancy Pryer, une post-doc de notre labo, a cloné SEC13 et montré qu'il code pour une petite protéine cytosolique qui contient une série de répétitions WD-40, très semblable à la sous-unité $\beta$ de la protéine $G$ (Prayer et al., 1993). Les membres de cette famille ont une structure en hélice $\beta$ à 7 branches, commune aux protéines impliquées dans des interactions réversibles entre protéines à multi-sous-unités. Nina Salama, une étudiante pré-doctorante très vivante du labo, a utilisé la réaction de bourgeonnement de Rexach pour purifier une forme fonctionnelle de Sec13p et révélé que celui-ci co-purifie avec une sous-unité additionnelle, que nous avons clonée et caractérisée comme un nouveau gène SEC, SEC31 (Salama et al., 1993). Avec ce dernier morceau du puzzle, nous avons découvert que la réaction de bourgeonnement était entretenue par des membranes isolées, accompagnées de Sar1p, Sec23/24p et Sec13/31p recombinants purifiés, Sec16p étant probablement apporté par la fraction membranaire. Une analyse fonctionnelle complète du mécanisme de bourgeonnement vésiculaire était donc maintenant à portée de main.

\section{COPII est responsable du bourgeonnement vésiculaire à partir du RE}

Nous avions peu de d'indices sur le mécanisme du bourgeonnement vésiculaire accompli par les protéines Sec purifiées de notre collection. Le laboratoire de Rothman avait identifié et caractérisé un nouveau complexe de protéines de revêtement, le coatomère, requis pour le bourgeonnement au cours du transport dans le complexe de Golgi (Malhotra et al., 1989). Il suggérait que ce manteau était peut être également nécessaire au trafic vésiculaire à partir du RE, mais nous ne trouvions pas de données concernant les sousunités du coatomère dans notre assortiment purifié de protéines Sec. De plus, nous avions cloné et caractérisé un gène $S E C$ différent, qui code pour une sous-unité du coatomère et, bien que le mutant sec21 soit bloqué dans le trafic à partir du RE, il ne s'intégrait pas bien dans une des classes mutantes de Kaiser; nous attribuions son effet sur le trafic à partir du RE à un amas de protéines-cargo qui s'accumulent, lorsque la fonction du Golgi est interrompue (Hosobuchi et al., 1992).

Plusieurs éléments clés, qui se mirent en place dans les années 1990, appuyèrent nos efforts. Deux nouveaux post-docs merveilleux du labo, Charles Barlowe et Tohru Yoshihisa, ont découvert un cycle d'hydrolyse et d'échange du GTP sur Sar1p. Tohru a trouvé que la sous-unité Sec23 est un catalyseur du cycle d'hydrolyse du GTP (GAP) spécifique pour Sar1p et Charlie a vu que le domaine cytoplasmique de Sec12p catalyse un échange de nucléotides sur Sar1p (Barlowe \& Schekman, 1993; Yohihisa et al., 1993). Plusieurs années plus tard, Bruno Antonny, un biophysicien extraordinairement habile et intuitif, a découvert que la sous-unité Sec 31 du complexe hétérotétramèrique 13/31 accélère dix fois l'activité GAP de Sec23 (Antonny et al., 2001). Il était clair qu'un événement d'assemblage coordonné, contrôlé par la liaison au GTP et son hydrolyse, encadrait le processus de bourgeonnement. Étant donné la 


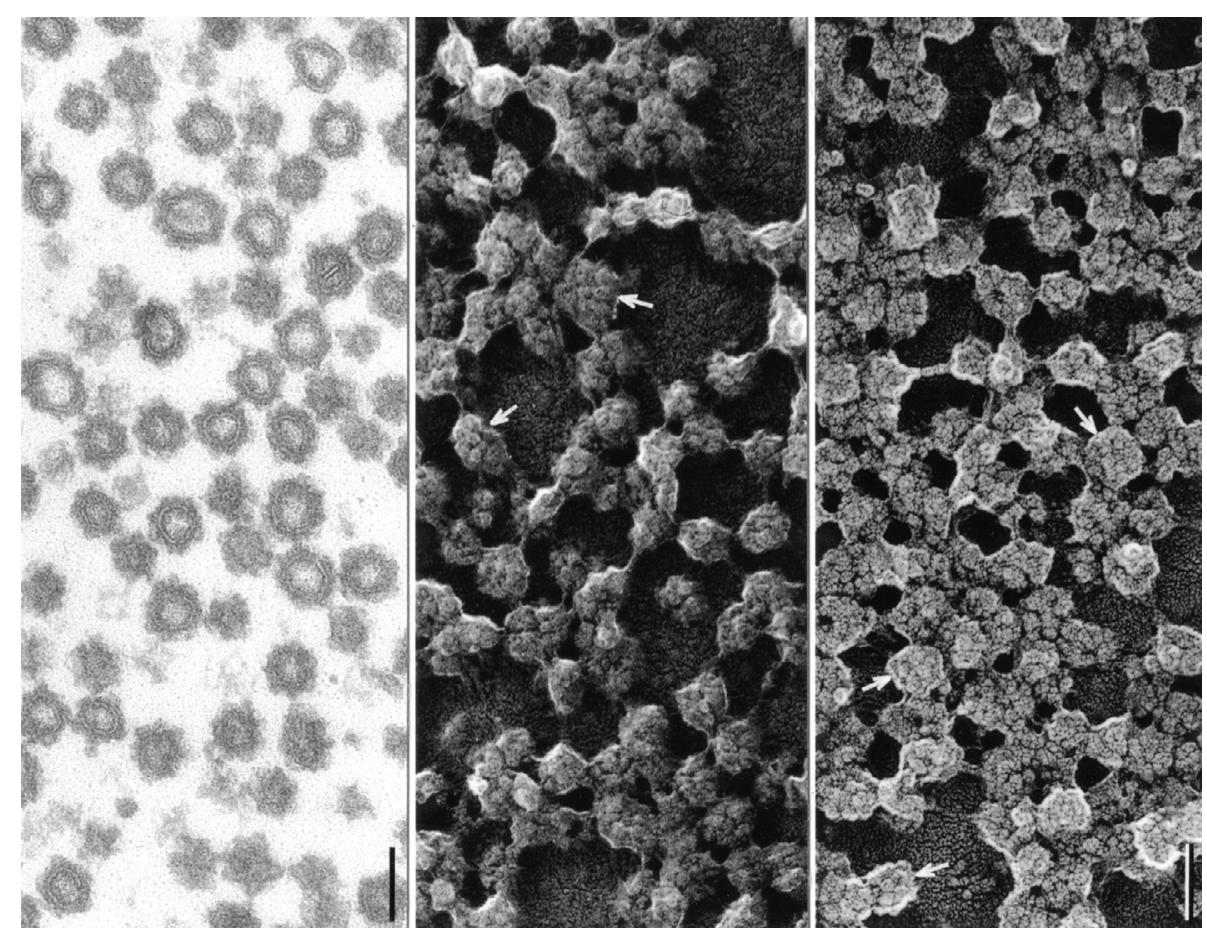

Fig. 8. Coupe ultrafine en microscopie électronique à transmission et images de microscopie à balayage de vésicules COPII. Barres $=100 \mathrm{~nm}$. Avec la permission de Lelio Orci, Genève.

découverte par Rothman du rôle de la liaison au GTP dans le contrôle de l'assemblage du coatomère et du bourgeonnement vésiculaire sur les membranes golgiennes, nous étions préparés à la découverte d'un nouveau complexe du manteau (Mélançon et al., 1987).

Le destin est intervenu sous la forme d'un appel téléphonique du maestro de la morphologie membranaire, Lelio Orci, de la Faculté de Médecine de l'Université de Genève. Orci a énormément contribué à la découverte des étapes morphologiques de la formation des vésicules et de leur fusion dans le complexe de Golgi au cours de la réaction de transport acellulaire révélée dans le labo de Rothman. Son habileté était si extraordinaire que j'ai essayé, mais en vain, de susciter son intérêt, lorsque notre travail a mis en évidence un rôle pour la clathrine dans l'obtention d'une enzyme golgienne, semblable à sa découverte de l'organisation de la clathrine et du processing de la proinsuline dans les cellules $\beta$ du pancréas (Orci et al., 1987).

Son appel en 1990 était motivé par notre publication récente de l'analyse de Kaiser sur les catégories de vésicules qui assurent le trafic à partir du RE. Lelio a pris en pitié la qualité « primitive» de nos coupes ultrafines pour l'analyse au microscope électronique et a gracieusement proposé sa collaboration pour examiner l'organisation des protéines Sec impliquées dans la formation des vésicules du RE. Son premier succès fut l'utilisation de notre anticorps contre la protéine de levure Sec23p pour localiser son homologue mammalien, précisément à son site de sortie, sur des coupes de tissu pancréatique (Orci et al., 1991). Mais l'enthousiasme le plus fort explosa lorsqu'il découvrit un nouveau manteau qui entourait les vésicules formées au cours d'une réaction avec des membranes de levure et nos protéines Sec purifiées. Barlowe avait isolé ces vésicules et nous avions déjà vu un soupçon de manteau sur les coupes fines préparées par mon habile technicienne de microscopie électronique, Susan Hamamoto, mais les images produites par Orci coupaient le souffle (figure 8). Nous avons appelé ce nouveau manteau COPII et suggéré que celui de Rothman/Orci soit appelé COPI (Barlowe et al., 1994). Je considère que c'est un des grands privilèges de ma carrière d'avoir eu pendant plus de 20 ans la joie d'une collaboration continue avec Orci, un intellectuel et un expérimentateur de la plus grande envergure.

$\mathrm{Au}$ cours d'une collaboration initiale cruciale, Orci et un nouveau post-doc du labo, Sebastian Bednarak, ont défini le RE comme le site morphologique du bourgeonnement de COPII. Sebastian a isolé des noyaux de levure comme source de membranes du RE purifiées et, avec Orci, a montré que les protéines COPII, et curieusement également les COPI, forment des bourgeons et incorporent des molécules-cargo venant de la membrane nucléaire externe. À l'aide d'un test de liaison séquentielle, Sebastian a démontré que COPII 
s'assemble en segments, en liant d'abord Sar1p et Sec23/24p qui forment la couche interne du manteau, Sec13/31p donnant ensuite la couche externe du manteau (Bednarek et al., 1995).

Ayant alors un ensemble de protéines cytosoliques à notre disposition, nous avons fixé notre attention sur la contribution des protéines de membrane et des lipides, en essayant de définir les besoins minimaux du bourgeonnement des vésicules.

Sec16 représentait la partie de la machinerie la plus évidente qui n'était pas prise en compte dans notre reconstitution. Deux stagiaires post-doctoraux successifs, Joe Campbell et Frantisek Supek, ont défini les conditions dans lesquelles on pouvait observer un rôle de Sec16p dans la réaction de bourgeonnement (Campbell \& Schekman, 1997; Supek et al., 2002). Eugene Futai a réussi à purifier le Sec16p recombinant et réuni les conditions dans lesquelles il contrôlait le cycle de la GTPase, médié par l'interaction de toutes les protéines COPII et de Sar1 (Kung et al., 2011). Pourtant maintenant encore, il n'est pas clair que Sec16 participe activement au cycle de bourgeonnement des vésicules ou joue plutôt un rôle régulateur en organisant les protéines COPII au site de sortie du RE.

Nous avons supposé que l'assemblage du manteau était régulé par la disponibilité des protéines membranaires transportées. Tom Yeung, un étudiant du labo, a montré, par le test d'incorporation d'une protéine SNARE, que les membranes isolées à partir de cellules traitées à la cycloheximide, par conséquent purgées des protéines nouvellement synthétisées, étaient parfaitement actives pour bourgeonner en vésicules à COPII (Yeung et al., 1995). Bien que le cargo biosynthétique ne soit pas forcément essentiel au bourgeonnement vésiculaire, nous avons suggéré que les protéines qui cyclent entre le $\mathrm{RE}$ et le Golgi pourraient constituer un élément essentiel de la contribution membranaire à la formation d'un bourgeon COPII (Springer et al., 1999).

Pour tester directement le rôle des protéines membranaires et des lipides dans le bourgeonnement, Yeung a essayé de solubiliser la membrane avec des détergents pour voir si des composants de ces catégories pourraient être reconstitués en liposomes capables de faire bourgeonner des vésicules COPII synthétiques. À notre surprise, Yeung et un jeune stagiaire post-doc méticuleux, Ken Matsuoka, ont montré de manière systématique que les vésicules COPII synthétiques bourgeonnaient et pouvaient être isolées sur gradient de densité à partir de liposomes phospholipidiques purs de composition définie, si la réaction était réalisée en présence d'un analogue non hydrolysable du GTP (Matsuoka et al., 1998). Bruno Antonny a mis au point un élégant essai en lumière dispersée et en temps réel, pour suivre l'assemblage par étapes et le désassemblage du manteau dans des milieux d'incubation contenant du GTP ou un analogue non hydrolysable (Antonny et al., 2001). Eugene Futai montra ensuite que le GTP peut remplacer l'analogue non hydrolysable pour produire une membrane stable CopII recouverte, à condition que soit ajouté à la réaction le domaine cytoplasmique du catalyseur d'échange de nucléotide de Sar1p, Sec12p, qui stabilise probablement le manteau grâce à des cycles répétés d'échanges du nucléotide GTP. Curieusement, ces réactions s'arrêtaient, alors qu'il y avait des bourgeons sur les liposomes, mais peu ou pas de vésicules COPII complètes (Futai et al., 2004). Plus récemment, Kirsten Bacia, une autre stagiaire postdoc, a reconstitué la réaction de bourgeonnement sur des vésicules géantes unilamellaires, où le processus peut être visualisé par microscopie photonique et de fluorescence, sans intervention de manipulations potentiellement dommageables, comme par exemple la centrifugation. Dans ces conditions, les incubations contenant les protéines COPII et du GTP non hydrolysable produisent de longs tubules recouverts, multilobés avec des points de constriction réguliers mais présentent peu d'aspects de fission vésiculaire (Bacia et al., 2011). La nature de la réaction de fission de COPII reste inconnue mais semble conditionnée par la régulation spatiale de la liaison du GTP et de son hydrolyse au collet du bourgeon vésiculaire.

L'évènement initial qui mène à un bourgeon pourrait commencer quand Sar1p acquiert du GTP par interaction avec Sec12. L'analyse structurale a montré que la forme soluble liée au GDP de Sar1 protège une hélice N-terminale amphipathique dans un sillon de la protéine repliée (Huang et al., 2001). L'échange de nucléotides déplace le N-terminal et rend le Sarp1 activé hautement insoluble et prédisposé à l'insertion dans la membrane. Marcus Lee, un post-doc plein d'intuition, a pensé que l'inclusion du N-terminal dans la bicouche peut déplacer les phospholipides latéralement et créer une asymétrie locale dans la surface des deux feuillets, tout à fait comme l'avait proposé Sheetz et Singer des décennies plus tôt avec l'hypothèse du « couple double couche » (Sheetz \& Singer, 1974). Dans une série d'expériences élégantes en collaboration avec Orci, Lee avait montré que Sar1p promeut la formation de tubules membranaires à partir de liposomes synthétiques, dépendant de l'insertion de l'hélice N-terminale amphipathique et que cette insertion est nécessaire à la formation des vésicules de COPII in vitro et au transport des protéines in vivo (Lee et al., 2005).

Des progrès prodigieux ont été faits dans l'analyse du manteau COPII, principalement par les laboratoires de Jonathan Goldberg et William Balch (Bi et al., 2002; Stag et al., 2006; Fath et al., 2007). Nous disposons maintenant d'explications détaillées 
du mécanisme de polymérisation des deux feuillets du manteau et d'un aperçu critique de l'échafaudage complexe qui forme le feuillet externe : un treillis polyédrique régulier que Balch a découvert dans une réaction d'auto-assemblage avec l'hétérotétramère mammalien purifié Sec13/31. Une ancienne collaboratrice post-doc, Giulia Zanetti, a récemment visualisé en microscopie cryoélectronique le réseau de COPII en treillis formé à la surface d'un liposome synthétique (Zanetti et al., 2013). Malgré le peu d'indications qui suggèrent des différences fonctionnelles ou structurales entre les protéines COPII des mammifères et celles de la levure, les mammifères ont la capacité de réguler la taille du manteau pour contenir des complexes de grande taille ou de forme irrégulière, comme les lipoprotéines et le pro-collagène. Une modification posttraductionnelle, l'ubiquitylation de Sec31, peut servir à réguler certains aspects de l'assemblage du manteau pour créer un transporteur plus malléable (Jin et al., 2012).

Une connexion inattendue entre la structure et la fonction des deux feuillets du manteau COPII a abouti à la découverte d'une mutation de la sous-unité Sec23A humaine. Simon Boyadjiev et Waffa Eyaid, un collègue saoudien, ont examiné une famille bédouine dans laquelle les enfants présentaient une rare malformation crânio-faciale. La mutation récessive est localisée à un résidu phénylalanine invariant, correspondant à une position sur la structure du Sec23p de la levure exposée à l'inverse de celle prévue pour aboutir au côté cytoplasmique de RE; ce résidu, à l'époque, n'avait pas de rôle particulier connu dans la fonction du manteau ou de son assemblage. Orci a examiné des fibroblastes en culture primaire de peau de l'un des enfants affectés et observé une distorsion profonde du RE et une accumulation de procollagène compatible avec un grave défaut de sécrétion (Boyadjiev et al., 2006). Heureusement pour nous, Jinoh Kim, un courageux post-doc du labo, avait méthodiquement perfectionné une réaction de bourgeonnement vésiculaire COPII en utilisant des membranes isolées de cellules de mammifères cultivées (Kim et al., 2005). Chris Fromme, un autre post-doc ambitieux et adroit, continua cette entreprise pour reconstituer la déficience observée dans le mutant Sec23A humain F382L. Chris a trouvé les conditions qui reproduisent le défaut de bourgeonnement et montré que celui-ci pouvait être supprimé en augmentant le niveau de Sec13/31 humain recombinant dans une réaction de bourgeonnement. De plus, il a montré, grâce à toutes les protéines COPII mammaliennes purifiées, que le mutant de Sec23A F382L avait des difficultés à établir le contact avec le complexe Sec13/31, ce qui se reflétait dans l'hydrolyse réduite du Sarp1-GTP (Fromme et al., 2007). Au même moment, le labo de Goldberg avait résolu la structure de l'hétérodimère Sec23/24 de levure en complexe avec un fragment de Sec31 de levure qui stimule l'activité GAP de Sec23p (Bi et al., 2007). Le point de contact le plus étroit entre $\mathrm{Sec} 31$ et $\mathrm{Sec} 23$ était situé à quelques angströms de la position correspondant au résidu humain F382. Ainsi la structure de la protéine de levure et le déficit fonctionnel résultant de la mutation chez les humains pouvaient être parfaitement réconciliés.

\section{Le manteau COPII guide la sélection de la cargaison chez la levure et dans les cellules et les tissus de mammifères}

Au début des années 1990, selon le concept dominant, le tri des protéines sécrétoires et des protéines résidentes du RE avait lieu après la sortie de la charge hors du RE, par l'intermédiaire de récepteurs de récupération qui ramenaient les protéines résidentes au RE. Des arguments forts en faveur de ce modèle ont été fournis par la découverte et la caractérisation d'un signal de récupération et d'un récepteur pour les protéines solubles résidentes du RE, comme par exemple la chaperonne luminale hsp70, BiP (Semenza et al., 1990) Des mesures du taux de trafic de certaines protéines artificielles introduites dans la voie de sécrétion plaident contre le besoin d'un tri actif des protéines sécrétoires en route le long du trajet (Wieland et al., 1987). De plus, deux protéines majeures sécrétées dans le foie ne semblent pas se concentrer dans les bourgeons qui se forment au site de sortie du RE, mais plus tard au point de récupération des protéines résidentes, médiée par COPI (MartinezMenaguez et al., 1999).

Bien que cette question continue à faire l'objet de controverses importantes (Thor et al., 2009), les résultats de notre réaction de bourgeonnement, au cours de laquelle les protéines résidentes sont en majeure partie exclues des vésicules COPII formées in vitro, sont en faveur d'une explication alternative selon laquelle un tri actif de protéines accompagne la réaction de bourgeonnement et que la récupération de protéines par les récepteurs de tri dans la membrane golgienne peuvent représenter un mécanisme de soutien renforçant les évènements primaires dans le RE (Rexach \& Schekman, 1991; Barlowe et al., 1994). Des preuves solides développées pendant les 15 dernières années documentent un rôle pour les récepteurs de cargaison localisés dans le RE et pour une sous-unité particulière du manteau COPII, Sec $24 \mathrm{p}$, dans le tri par concentration de protéines de membrane et de charge luminales solubles vers les vésicules de transport COPII (Zanetti et al., 2011).

Si les protéines sécrétoires sont activement triées dans les vésicules COPII, il devrait être possible de 
définir un signal de triage en isolant des mutations ponctuelles qui produiraient des précurseurs correctement repliés qui persistent dans la lumière du RE. En pratique cela s'est révélé difficile parce qu'il n'est pas certain qu'une protéine mutante puisse passer le contrôle de qualité des protéines mal repliées pour la rétention dans le RE. Irène Schauer, l'une des premières étudiantes de mon labo, avait isolé un tel mutant d'invertase qui s'accumulait dans le RE sous forme d'une enzyme, parfaitement active, correctement assemblée et totalement soluble, mais qui était sécrétée à partir du RE 4 à 5 fois plus lentement que l'enzyme normale (Schauer et al., 1985).

En ce qui concerne les protéines-cargo membranaires, les données de départ plaidaient en faveur d'une interaction directe avec les sous-unités internes du manteau COPII, Sar1p et sec23/24, avant la formation complète de la vésicule recouverte. Meta Kuehn, un post-doc du labo, a détecté une interaction de la perméase de la membrane plasmique et des protéines SNARE mais il n'y avait pas d'interaction des protéines luminales résidentes du RE avec les sousunités COPII pendant une incubation des membranes en présence d'un analogue non hydrolysable du GTP (Kuehn et al., 1998). Le laboratoire de Bill Balch a observé une interaction analogue du Sec23/24 de mammifère avec un intermédiaire de transit de la protéine G du VSV et découvert que l'interaction dépend d'une séquence de tri C-terminale, ..DxE., dans la protéine G (Nishimura \& Balch, 1997). Sebastian Springer a renforcé cette idée avec l'observation d'un complexe stable et sélectif entre Sarp1, sec 23/24 et des formes recombinantes pures du domaine cytosolique de deux protéines SNARE du RE, Bet1p et Bos1p (Springer \& Schekman, 1998).

Pour les protéines sécrétoires, la meilleure preuve de tri sélectif vient de la découverte de récepteurs $\mathrm{du}$ RE qui assument cette fonction. Le laboratoire de David Ginsburg a identifié les gènes impliqués dans une hémophilie combinée rare au cours de laquelle deux facteurs de coagulation, V et VIII, sont retardés dans le RE. Un gène code pour une protéine membranaire affine pour les lectines ERGIC53 (ou LMAN1) (Nichols et al., 1998), qui cycle entre le RE et le Golgi et qui est activement empaquetée dans des vésicules COPII au cours d'une réaction de bourgeonnement acellulaire obtenue à partir de cellules mammaliennes cultivées perméabilisées (Nichols et al., 1998). On a supposé que les domaines protéiques fortement glycosylés des facteurs V et VIII interagissent avec le domaine luminal de liaison aux lectines de ERGIC53 pour promouvoir leur sortie du RE (Moussali et al., 1999). L'évaluation du rôle exact d'ERGIC53 en tant que récepteur de tri attend la mise au point d'une technologie pour mesurer l'incorporation d'un facteur de coagulation dans les vésicules de transport.
Chez la levure, une percée est venue de la découverte par Charles Barlow, qui a maintenant son propre laboratoire à Dartmouth, du récepteur de tri nécessaire pour le transport du précurseur du facteur $\alpha$. Au cours d'un examen des protéines membranaires dans les vésicules COPII isolées, Barlowe a caractérisé Erv29p, une protéine qui n'était sortie d'aucun crible génétique (Belden \& Barlowe, 1996). La délétion d'ERV29 a produit une souche viable porteuse d'un défaut prononcé de la sécrétion du facteur $\alpha$, l'élément mature issu du processing protéolytique du précurseur dans le trans-Golgi (Belden \& Barlowe, 2001). Malheureusement ERV29 n'a pas été détecté dans les sélections classiques pour les mutants de levure déficients en phéromone parce que même le retard de sécrétion (x30) du facteur $\alpha$, observé dans la souche d'erv29 mutée, est incapable de réduire l'état d'équilibre de la phéromone sécrétée au dessous du niveau nécessaire pour produire une souche infertile. D'autres travaux ont montré qu'ERV29 accélère le transport de la protéase vacuolaire du $\mathrm{RE}$ et probablement d'autres protéines, sauf, notablement, celui de l'invertase (Caldwell et al., 2001). Barlowe a ensuite démontré qu'Erv29p est requise pour empaqueter le précurseur du facteur $\alpha$ dans des vésicules CopII in vitro et pour localiser les résidus responsables de l'interaction d'Erv29p avec le précurseur (Kuehn et al., 1996).

On pourrait argumenter que ERGIC53 et Erv29p servent essentiellement de chaperonnes de repliement, spécifiques d'espèce, qui accompagnent les protéinescargo vers le cis-Golgi et sont ensuite recyclées puis utilisées dans le RE et que, en leur absence, les molécules-cargo correspondantes restent légèrement dépliées et sujettes à la rétention par le contrôle de qualité. Tel paraît être le cas pour un grand nombre de chaperonnes membranaires du RE spécifiques d'espèce, par exemple Shr3p requise pour le transport des perméases d'aminoacides chez la levure, qui restent dans le RE et n'accompagnent pas la charge dans les vésicules COPII (Kuehn et al., 1996). Toutefois, Per Malkus, un étudiant de mon labo, a montré que le précurseur du facteur $\alpha$ est chimiquement concentré trois fois par rapport à un marqueur soluble du flux de masse, un glycotripeptide, à l'intérieur des vésicules COPII produites dans une réaction de bourgeonnement. Ce résultat plaide pour un modèle de tri actif, ce qui s'oppose à un flux continu pour la capture des protéines de charge dans les vésicules COPII (Malkus et al., 2002).

Une ligne d'arguments complémentaires démontre que le manteau COPII, et plus spécifiquement la sousunité Sec24p, dirige la sélection des charges pendant le bourgeonnement. La levure a trois paralogues de Sec24, les mammifères en ont quatre, et les données génétiques et biochimiques montrent que plusieurs 
sont responsables de la capture de sous-ensembles particuliers de protéines-cargo membranaires. Le labo de Chris Kaiser au MIT a été le premier à reconnaître le rôle important du paralogue de SEC24 qu'il a appelé $L S T 1$ dans le transport de l'ATPase majeure de la membrane plasmique, Pma1p (Roberg et al., 1999). Bien que la délétion de $L S T 1$ ne soit pas un événement létal, les cellules sont souffreteuses et la présentation en surface de l'ATPase y étant déficiente, celle-ci s'accumule dans le RE. Kaiser a suggéré que Lst1P pourrait former un complexe alternatif avec Sec23p pour améliorer le conditionnement de Pma1p et que, en son absence, le Sec24p normal pourrait ne pas trier correctement Pma1p vers les vésicules COPII. Yuval Shimoni, un post-doc de mon labo, l'a prouvé directement, à l'aide d'une réaction de bourgeonnement de Pma1p programmée avec soit Sec23/Sec24p, soit Sec23/LST1P. Lst1p promeut de manière spectaculaire le conditionnement de Pma1p dans les vésicules CPII in vitro (Shimoni et al., 2000).

Liz Miller, une post-doc merveilleusement enthousiaste et talentueuse, est arrivée au labo pour explorer les détails du tri des charges opéré par COPII. Sur la lancée de l'isolement par Shimoni d'un Sec23/Lst1p fonctionnel, Liz a mis en évidence un spectre remarquablement différent de protéines membranaires empaquetées dans des vésicules produites par un hétérodimère alternatif, présentant une anomalie de l'incorporation du précurseur du facteur $\alpha$, probablement parce que Lst1p n'est pas requis pour reconnaître la plupart des charges membranaires ou des récepteurs protéiques de tri, y compris Erv29p (Miller et al., 2002). Liz a ensuite entrepris une étude détaillée de mutagenèse pour identifier les aminoacides de Sec24p dévolus au tri de protéines-cargo transportées particulières (Miller et al., 2003). Elle a trouvé des allèles mutés qui étaient globalement létaux, lorsque l'un ou les deux autres paralogues de SEC24 avaient subi une délétion. Une de ces mutations a été repérée sur un site de liaison que Jonathan Goldberg avait défini structuralement sur une surface latérale de Sec24p, qui interagit avec le signal de tri ..DXE.., estimé important par Bill Balch pour le trafic de la protéine G du VSV issue du RE (Nishimura \& Balch, 1997; Mosseseva et al., 2003). En utilisant la réaction de bourgeonnement, Liz a montré que les mutations de Sec24p situées dans ce site de liaison étaient parfaitement capables de faire bourgeonner certaines charges mais pas celles qui dépendent du motif de tri ..DXE... Per Malkus a identifié un motif ..DXD.. dans le domaine cytoplasmique C-terminal des perméases d'aminoacides de levure, dont Liz a montré qu'il était reconnu de manière parfaitement adéquate par un mutant sec24p qui ne reconnaît pas le motif ..DXE.. (Malkus et al., 2002). Ces résultats, ainsi que de nombreux autres depuis, ont construit une image de la sous-unité Sec24p du manteau, comportant des sites de liaison des charges multiples et indépendants qui se combinent avec les deux paralogues Sec24p, ce qui aide à expliquer comment le répertoire diversifié de molécules transportées peut être déchiffré à l'aide d'un code combinatoire.

Un assortiment encore plus important de protéines-cargo est trouvé dans le RE mammalien. Deux exemples frappants de la spécificité du tri des charges accompli par ces paralogues mammaliens de SEC24 ont été rapportés. Des mutations sur la chaîne terminale du gène $S E C 24 B$ de souris provoquent un défaut majeur de fermeture du tube neural, désigné par le terme de crânio-rachiscisis (Merte et al., 2010; Wansleeben et al., 2010). La même anomalie a été vue dans les délétions des formes neurales de récepteurs de signalisation tels que Frizzled et Vangl, deux protéines de surface de l'épithélium neural, qui sont assemblées sur les membranes plasmiques distales et proximales de cellules neurales épithéliales, respectivement (Wu \& Mlodzik, 2009). À l'aide de cellules mammaliennes en culture perméabilisées, Devon Jensen, un étudiant de mon labo, collaborant avec le laboratoire de David Ginty, a découvert que la protéine Sec24b stimulait spécifiquement l'emballage de la protéine Vangl2 dans les vésicules COPII, encore une fois en accord avec la séquence du tri sélectif de structure des protéines membranaires au niveau du RE (Merte et al., 2010). Des allèles mutants du SEC24B humain peuvent se trouver chez des enfants affectés d'une forme génétique de spina bifida. Xiaowei Chen dans le labo de David Ginsburg a vu qu'une préférence marquée pour une certaine charge était conférée par un autre paralogue, SEC24A. La délétion de SEC24A chez la souris conduit à une décroissance remarquable des taux de cholestérol dans le sang que Chen a pu attribuer à un défaut de transport et de sécrétion par le RE d'une protéine sérique soluble PCSK9, qui contrôle l'itinéraire du récepteur des LDL (Chen et al., 2013). Des niveaux plus bas de PCSK9 permettent au récepteur des LDL de cycler de manière efficace et de contrôler la biosynthèse du cholestérol, ce qui explique le faible niveau de cholestérol chez les animaux dont la sécrétion de PCSK9 est déficiente. Les résultats de Chen indiquent que l'export de PSKC9 hors du RE est réalisé par un récepteur de tri qui est reconnu et emballé dans les vésicules COPII par SEC24A. La nature de ce récepteur et son rôle dans le tri d'autres molécules-cargo restent à découvrir. Il semble probable que beaucoup d'autres récepteurs de tri de ce type dans le RE seront découverts, ajoutant au tableau d'un processus de sélection des charges par le manteau COPII et, par extension, par d'autres manteaux impliqués dans le trafic intracellulaire des membranes et des protéines solubles. 


\section{Conclusions et remerciements}

Résumer quelques 40 années de travail est une expérience intimidante, cependant trois conclusions clés émergent du travail que j'ai décrit :

1. La sécrétion et l'assemblage de la membrane plasmique sont physiquement et fonctionnellement liés par une série d'organites intermédiaires obligés.

2. La translocation de peptides et la machinerie du trafic vésiculaire se sont conservées au cours d'un milliard d'années d'évolution.

3. Le manteau COPII trie les molécules-cargo grâce à la reconnaissance de signaux de transport et déforme physiquement la membrane du RE pour créer des vésicules bourgeonnées.

Les limites de place et de temps ont rendu impossible pour moi de citer les contributions nombreuses de près de 200 étudiants, stagiaires et collègues avec qui j'ai eu le privilège de travailler pendant toutes ces années. Bien que j'achève cette histoire ici, le travail continue dans mon labo, malgré les nombreuses interruptions que l'appel venant de Stockholm a apportées dans ma vie. Je suis reconnaissant aux membres actuels de mon labo pour leur patience cette année-là, et encore beaucoup plus pour l'enthousiasme et le dévouement qu'ils apportent au travail en cours. Rien de tout cela n'aurait été possible sans l'amour constant et le soutien de ma famille et de mes amis, et l'investissement avisé que les USA et la Californie ont fait en construisant des lieux d'éducation et de recherche à nuls autres pareils.

Le thème de l'assemblage des membranes et du trafic vésiculaire est riche d'opportunités et reste un domaine d'un potentiel immense pour des découvertes à l'échelle de la molécule ou même de l'atome dans les années qui viennent. Les liens entre la découverte de base et les applications pratiques et médicales sont certainement plus tangibles aujourd'hui que lorsque j'ai commencé mon travail personnel en 1976. Pourtant, j'ai confiance que la poursuite d'une recherche fondamentale indépendante des applications pratiques continuera à motiver les jeunes intellectuels et que les agences, publiques et privées, qui ont fait de la découverte une aventure pour moi, continueront à le faire aussi longtemps que nous aurons soif de la connaissance du monde de la nature.

\section{Références}

Antonny, B., Madden, D., Hamamoto, S., Orci, L., and Schekman, R. (2001) Dynamics of the COPII coat with GTP and stable analogues. Nature Cell Biol, 3, 531-537.
Bacia, K., Kutai, E., Prinz, D., Meister, A., Daum, S., Glatte, D., Briggs, J.A.G., and Schekman, R. (2011) Multibudded tubules formed by COPII on artificial liposomes. Sci Rep, 1, 17.

Baker, D., Hicke, L., Rexach, M., Schleyer, M., and Schekman, R. (1988) Reconstitution of Sec gene product-dependent intercompartmental protein transport. Cell, 54, 335-344.

Barlowe, C., and Schekman, R. (1993) SEC12 encodes a guanine nucleotide exchange factor essential for transport vesicle formation from the ER. Nature, 365, 347-349.

Barlowe, C., d'Enfert, C., and Schekman, R. (1993) Purification and characterization of SAR1p, a small GTP-binding protein required for transport vesicle formation from the endoplasmic reticulum. J Biol Chem, 268, 873-879.

Barlowe, C., Orci, L.,Yeung, T., Hosobuchi, M., Hamamoto, S., Salama, N., Rexach, M.F., Ravazzola, M., Amherdt, M., and Schekman, R. (1994) COPII: A membrane coat formed by Sec proteins that drive vesicle budding from the endoplasmic reticulum. Cell, 77, 895-907.

Barry, J., and Alberts, B. (1972) In vitro complementation as an assay for new proteins required for bacteriophage T4 DNA replication: Purification of the complex specified by T4 genes 44 and 62. Proc Nat Acad Sci USA, 69, 2717-2721.

Bednarek, S.Y., Ravazzola, M., Hosobuchi, M., Amherdt, M., Perrelet, A., Schekman, R., and Orci, L. (1995) COPI- and COPII-coated vesicles bud directly from the endoplasmic reticulum in yeast. Cell, 83, 1183-1196.

Belden W.J., and Barlowe C. (1996) Erv25p, a component of COPII-coated vesicles, forms a complex with Emp24, that is required for efficient endoplasmic reticulum to Golgi transport. J Biol Chem, 271, 26939-26946.

Belden, W.J., and Barlowe, C. (2001). Role of Erv29p in collecting soluble secretory proteins into ER-derived transport vesicles. Science, 294, 1528-1531.

Benzer, S. (1957) The elementary units of heredity. In a symposium on the chemical basis of heredity, edited by W.D. McElroy and B. Glass. Baltimore: The Johns Hopkins Press, pp 70-133.

Bernstein, M., Hoffmann, W., Ammerer, G., and Schekman, R. (1985) Characterization of a gene product (Sec53p) required for protein assembly in the yeast endoplasmic reticulum. J Cell Biol, 101, 2374-2382.

Bernstein, M., Kepes, F., and Schekman, R. (1989) SEC59 encodes a membrane protein required for core glycosylation in yeast. Mol Cell Biol, 9, 1191-1199.

Bi, X., Corpina, R. and Goldberg, J. (2002) Structure of the Sec23/24-Sar1 pre-budding complex of the COPII coat. Nature, 419, 271-277.

Bi, X., Mancias, J.D., and Goldberg, J. (2007) Insights into COPII coat nucleation from the structure of Sec23Sar1 complexed with the active fragment of Sec31. Dev Cell, 13, 635-645. 
Blobel, G. and Dobberstein B. (1975a) Transfer of proteins across membranes. I. Presence of proteolytically processed and unprocessed nascent immunoglobulin light chains on membrane-bound ribosomes of murine myeloma. J Cell Biol, 67, 835-851.

Blobel G. and Dobberstein B. (1975b) Transfer of proteins across membranes. II. Reconstitution of functional rough microsomes from heterologous components. J Cell Biol, 67, 852-862.

Boer P., Van Rijn H.J., Reinking A., and Seryn-Parvé E.P. (1975) Biosynthesis of acid phosphatase of baker's yeast. Characterization of a protoplast-bound fraction containing precursors of the exo-enzyme. Biochim Biophys Acta, 377, 331-342.

Böhni, P.C., Deshaies, R.J., and Schekman, R.W. (1988) $S E C 11$ is required for signal peptide processing and yeast cell growth. J Cell Biol, 106, 1035-1042.

Boyadjiev, S.A., Fromme, J.C., Ben, J., Chong, S.S., Nauta, C., Hur, D.J., Zhang, G., Hamamoto, S., Schekman, R., Ravazzola, M., Orci, L., and Eyaid, W. (2006) Cranio-lenticulo-sutural dysplasia is caused by a SEC23A mutation leading to abnormal endoplasmic-reticulum-to-Golgi trafficking. Nature Gen, 38, 1192-1197.

Brenner, S. (1974) The genetics of Canorhabditis elegans. Genetics, 77, 71-94.

Brutlag, D., Schekman, R.W., and Kornberg, A. (1971) A possible role for RNA polymerase in the initiation of M13 DNA synthesis. Proc Natl Acad Sci USA, 68, 2826 .

Byers, B., and Goetsch, L. Duplication of spindle plaques and integration of the yeast cell cycle. (1974) Cold Spring Harb Symp Quant Biol, 38, 123-131

Byers, B., and Goetsch, L. (1976) A highly ordered ring of membrane-associated filaments in budding yeast. J Cell Biol, 69, 717-721.

Cabib, E., and Bowers, B. (1971) Chitin and yeast budding. J Biol Chem, 246, 152-159.

Caldwell, S., Hill, K., and Cooper, A. (2001) Degradation of ER quality control substrates requires transport between the ER and Golgi. J Biol Chem, 276, 23296-23303.

Campbell, J.L., and Schekman, R. (1997) Selective packaging of cargo molecules into endoplasmic reticulumderived COPII vesicles. Proc Natl Acad Sci USA, 94, 837-842.

Chen, X.-Y,E., Baines, E., Yu, G., Sartor, M.A. Zhang, B., Yi, Z., Lin, J., Young, S.G., Schekman, R., and Ginsburg, D. (2013) SEC24A Deficiency Lowers Plasma Cholesterol through Reduced PCSK9 Secretion. Elife, April 9, 2, e00444.

Chirico, W.J., Waters, M.G., and Blobel, G. (1988) 70K heat shock related proteins stimulate protein translocation into microsomes. Nature, 332, 805-810.

De Lucia, P., and Cairns, J. (1969) Isolation of an E. coli Strain with a Mutation affecting DNA Polymerase Nature, 224, 1164-1166.
De Waard, A., Paul, A., and Lehman, I.R. (1965) The structural gene for deoxyribonucleic acid polymerase in bacteriophages T4 and T5. Proc Natl Acad Sci USA, $54,1241-1248$.

d'Enfert, C., Wuestehube, L.J., Lila, T., and Schekman, R. (1991) Sec12p-dependent membrane binding of the small GTP-binding protein Sar1p promotes formation of transport vesicles from the ER. J Cell Biol, 114, 663-670.

Deshaies, R., and Schekman, R. (1987) A yeast mutant defective at an early stage in import of secretory protein precursors into the endoplasmic reticulum. J Cell Biol, 105, 633-645.

Deshaies, R.J., Koch, B.D., Werner-Washburne, M., Craig, E.A., and Schekman, R. (1988) A subfamily of stress proteins facilitates translocation of secretory and mitochondrial precursor polypeptides. Nature, 332, 800805.

Eakle, K., Bernstein M., and Emr, S. (1988) Characterization of a component of the yeast secretion machinery: identification of the SEC18 gene product. Mol Cell Biol, 8, 4098-4109.

Edgar, R., and Wood, W., (1966) Morphogenesis of bacteriophage T4 in extracts of mutant-infected cells. Proc Natl Acad Sci USA, 55, 498-505.

Emr, S.D., and Silhavy, T.J. (1980) Mutations affecting localization of an Escherichia coli outer membrane protein, the bacteriophage lambda receptor. J Mol Biol, 141, 63-90.

Emr, S.D., Schauer, I., Hansen, W., Esmon, P., and Schekman, R. (1984) Invertase $\beta$-galactosidase hybrid proteins fail to be transported from the endoplasmic reticulum in yeast. Mol Cell Biol, 4, 2347-2356.

Epstein, R., Bolle, A., Steinberg, C., Kellenberger, E., Boy de la Tour, E., Chevalley, R., Edgard, R., Susman, M., Denhardt, G., and Leilausis, A. (1963) Physiological Studies of Conditional Lethal Mutants of Bacteriophage T4D. Cold Spring Harb Symp Quant Biol, 28, 375-394

Esmon, B., Novick, P., and Schekman, R. (1981) Compartmentalized assembly of oligosaccharides on exported glycoproteins. Cell, 25, 451-460.

Espenshade, P., Gimeno, R.E., Holzmacher, E., Teung, P., and Kaiser, C.A., (1995). Yeast SEC16 gene encodes a multidomain vesicle coat protein that interacts with Sec23p. J Cell Biol, 131, 311-324

Fangman, W., and Novick, A. (1968) Characterization of two bacterial mutants with temperature-sensitive synthesis of DNA. Genetics, 60, 1-17.

Fath, S., Mancias, J.D., Bi, X., and Goldberg, J. (2007) Structure and organization of coat proteins in the COPII cage. Cell, 129, 1325-1336.

Ferro-Novick, S., Novick, P., Field, C., and Schekman, R. (1984) Yeast secretory mutants that block the formation of active cell surface enzymes. J Cell Biol, 98, $35-43$.

Fries, E., and Rothman, J.E. (1980) Transport of vesicular stomatitis virus glycoprotein in a cell-free extract. Proc Natl Acad Sci USA, 77, 3870-3874. 
Fromme, J.C., Ravazzola, M., Hamamoto, S., Al-Balwi, M., Eyaid, W., Boyadjiev, S.A., Cosson, R., Schekman, R., and Orci, L. (2007) The genetic basis of a craniofacial disease provides insight into COPII coat assembly. Developmental Cell, 13, 623-634.

Futai, E., Hamamoto, S., Orci, L., and Schekman, R. (2004) GTP/GDP exchange by Sec12p enables COPII vesicle bud formation on synthetic liposomes. EMBO $J, 23,4146-4155$.

Gefter, M., Hirota, Y, Kornber, T., Wechsler, J., and Barnoux, C. (1971) Analysis of DNA polymerases II and III in mutants of Escherichia coli thermosensitive for DNA Synthesis. Proc Natl Acad Sci USA, 68, 3150-3153.

Gengyo-Ando, K., Kamiya, Y., Yamanaka, A., Kodaira, I.K., Nishiwaki, K., Miwa, J., Hori, I., and Hosono, R. (1993).The $C$. elegans unc-18 gene encodes a protein expressed in motor neurons. Neuron, 11, 703-711.

Gorlich, D., and Rapoport, T. (1993) Protein translocation into proteoliposomes reconstituted from purified components of the endoplasmic reticulum membrane. Cell, 75, 615-630.

Gorlich, D., Prehn, S., Hartmann, E., Kalies, K-U., and Rapoport, T. (1992) A mammalian homolog of SEC61p and SECYp is associated with ribosomes and nascent polypeptides during translocation. Cell, 71, 489-503

Goulian, M., and Kornberg, A. (1967) Enzymatic synthesis of DNA, XXIII, Synthesis of circular replicative form phage $\varphi$ X174 DNA. Proc Natl Acad Sci USA, $58,1723-1730$.

Goulian, M, Kornberg, A., and Sinsheimer, R.L. (1967) Enzymatic synthesis of DNA, XXIV. Synthesis of infectious phage $\varphi$ X174 DNA. Proc Natl Acad Sci USA, 58, 2321-2328.

Greenberg, G., Shelness, G., and Blobel, G. (1989) A subunit of the mammalian signal peptidase is homologous to the yeast SEC11 protein. J Biol Chem, 264, 15762-15765.

Griff, I.C., Schekman, R., Rothman, J.E., and Kaiser, C.A. (1992) The yeast SEC17 gene product is functionally equivalent to mammalian $\alpha$-SNAP protein. $J$ Biol Chem, 267, 12106-12115.

Groesch, M., Ruohola, H., Bacon, R., Rossi, G., and FerroNovick, S. (1990) Isolation of a functional vesicle intermediate that mediates ER-Golgi transport in yeast. J Cell Biol, 111, 45-53.

Hansen W., Garcia P., and Walter P. (1986) In vitro protein translocation across the yeast endoplasmic reticulum: ATP-dependent posttranslational translocation of the prepro-alpha-factor. Cell, 45, 397-406.

Hartwell, L., Mortimer, R., Culotti, J., and Culotti, M. (1973) Genetic control of cell division cycle in yeast: Genetic analysis of $c d c$ mutants. Genetics, 74, 267-286.

Haselbeck, A., and Schekman, R. (1986) Interorganelle transfer and glycosylation of yeast invertase in vitro. Proc Natl Acad Sci USA, 83, 2017-2021.

Henry, S., Atkinson, K., Kolat, A., and Culbertson, M. (1977) Growth and metabolism of inositol-starved Saccharomyces cerevisia. J Bact, 130, 472-484.
Hicke, L., Yoshihisa, T., and Schekman, R. (1992) Sec23p and a novel $105 \mathrm{kD}$ protein function as a multimeric complex to promote vesicle budding and protein transport from the ER. Mol Biol Cell, 3, 667-676.

Hinnen, A., Hicks, J., and Fink, G. (1978) Transformation of yeast. Proc Natl Acad Sci USA, 75, 1929-1933.

Hirano, H., Parkhouse, B., Nicholson, G., Lennox, E., and Singer, S.J., (1972) Distribution of saccharide residues on membrane fragments from a melanoma cell homogenate: Its implications for membrane biogenesis. Proc Natl Acad Sci USA, 69, 2945-2949.

Hirota, Y., Ryter, A., and Jacob, F. (1968) Thermosensitive mutants of E. coli affected in the processes of DNA synthesis and cellular division. Cold Spring Harb Symp Quant Biol, 33, 677-693.

Hosobuchi, M., Kreis, T., and Schekman, R. (1992) SEC21 is a gene required for ER to Golgi protein transport that encodes a subunit of a yeast coatomer. Nature, 360, 603-605.

Huang, M., Weissman, J., Béraud, S., Luan, P., Wang, C., Chen, W., Aridor, M., Wilson, I., and Balch, W. (2001) Crystal structure of Sar1-GDP at $1.7 \AA$. J Cell Biol, 155, 937-948.

Jin, L., Pahuja. K.B., Wickliffe, K.E., Gorur, A., Baumgartel, C., Schekman, R., and Rape, M. (2012) Ubiquitin-dependent regulation of COPII coat size and function. Nature, 482, 495-500.

Josse, J., Kaiser, A.D., and Kornberg, A. (1961) Enzymatic Synthesis of Deoxyribonucleic Acid: VIII. Frequencies of the nearest neighbor base sequences in deoxyribonucleic acid. J Biol Chem, 236, 864-875.

Kaiser, C.A., and Schekman, R. (1990) Distinct sets of $S E C$ genes govern transport vesicle formation and fusion early in the secretory pathway. Cell, 61, 723-733.

Kelly, R., Atkinson, M., Huberman, J., and Kornberg, A. (1969) Excision of Thymine Dimers and Other Mismatched Sequences by DNA Polymerase of Escherichia coli. Nature, 224, 495-501.

Kepes, F., and Schekman, R. (1988) The yeast SEC53 gene encodes phosphomannomutase. J Biol Chem, 263, 9155-9161.

Kim, J., Hamamoto, S., Ravazzola, M., Orci, L., and Schekman, R. (2005) Uncoupled packaging of amyloid precursor protein and presenilin 1 into COPII vesicles. J Biol Chem, 280, 7758-7768.

Kornberg, A., Lehman, I.R., Bessman, M.J., and Simms, E.S. (1956) Enzymatic synthesis of desoxyribonucleic acid. Biochim Biophys Acta, 21, 197-198.

Kornberg, T., and Gefter, M.L. (1970) DNA synthesis in cell-free extracts of a DNA polymerase-defective mutant. Biochem Biophys Res Commun, 40, 1348-1355.

Kuehn, M., Schekman, R., and Ljungdahl, P. (1996) Amino acid permeases require COPII components and the ER resident membrane protein in Shr3p for packaging into transport vesicles in vitro. J Cell Biol, 135, 585-595.

Kuehn, M.T., Herrmann, J.M., and Schekman, R. (1998) COPII-cargo interactions direct protein sorting into ER-derived transport vesicles. Nature, 391, 187-190. 
Kung, L.F., Pagant, S., Futai, E., D'Arcangelo, J.G., Buchanan, R., Dittmar, J.C., Reid, R.J.D., Rothstein, R., Hamamoto, S., Snapp, S., Schekman, R., and Miller, E.A. (2011) Sec24p and Sec16p cooperate to regulate the GTP cycle of the COPII coat. EMBO J, 31, 1014-1027.

Lee, M. C, Orci, L., Hamamoto, S., Futai, E., Ravazzola, M., and Schekman, R. (2005) Sar1p N-terminal helix initiates membrane curvature and completes the fission of a COPII vesicle. Cell, 122, 605-617.

Lemmon, S., and Jones, E. (1987) Clathrin requirement for normal yeast growth. Science, 238, 504-509.

Malhotra, V., Serafini, T., Orci, L., Shepherd, J.C., and Rothman, J.E. (1989) Purification of a novel class of coated vesicles mediating biosynthetic protein transport through the Golgi stack. Cell, 58, 329-336.

Malkus, P., Jiang, F., and Schekman, R. (2002) Concentrative sorting of secretory cargo proteins into COPII-coated vesicles. J Cell Biol, 159, 915-921.

Martinez-Menarguez, J., Geuze, H., Slot, J., and Klumpermann, J. (1999) Vesicular tubular clusters between the ER and Golgi mediate concentration of soluble secretory proteins by exclusion from COPI-coated vesicles. J Cell Biol, 98, 81-90.

Matsuoka, K., Orci, L., Amherdt, M., Bednarek, S.Y., Hamamoto, S., Schekman, R., and Yeung, T. (1998) COPII-Coated vesicle formation reconstituted with purified coat proteins and chemically defined liposomes. Cell, 93, 263-275.

Mélançon, P., Glick, B.S., Malhotra, V., Weidman, P.J., Serafini, T., Gleason, M.L., Orci, L., and Rothman, J.E. (1987) Involvement of GTP-binding "G" proteins in transport through the Golgi stack. Cell, 51, 1053-1062.

Merte, J., Jensen, D., Wright, K., Sarsfield, S., Wang, Y., Schekman, R., and Ginty, D.D. (2010) Sec24b selectively sorts Vang12 to regulate planar cell polarity during neural tube closure. Nature Cell Biol, 12, 41-46.

Miller, E., Antonny, B., Hamamoto, S., and Schekman, R. (2002) Cargo selection into COPII vesicles is driven by the Sec24p subunit. EMBO J, 21, 6105-6113.

Miller, E., Beilharz, T.H., Malkus, P.N., Lee, M.C.S., Hamamoto, S., Orci, L., and Schekman, R. (2003) Multiple cargo binding sites on the COPII subunit Sec 24 p ensure capture of diverse membrane proteins into transport vesicles. Cell, 114, 1-20.

Mosseseva, E., Bickford, L.C., and Goldberg, J., (2003) SNARE selectivity of the COPII coat. Cell, 114, 483-495.

Moussalli, M., Pipe, S.W., Hauri, H.P., Nichols, W.C., Ginsburg, D., and Kaufman, R.J. (1999) Mannosedependent endoplasmic reticulum (ER)-Golgi intermediate compartment-53-mediated ER to Golgi trafficking of coagulation factors V and VIII. J Biol Chem, $12,32539-32542$.

Nakano, A., and Muramatsu, M. (1989) A novel GTPbinding protein, Sar1p, is involved in transport from the endoplasmic reticulum to the Golgi apparatus. J Cell Biol, 109, 2677-2691.
Nakano, A., Brada, D., and Schekman, R. (1988) A membrane glycoprotein, Sec12p, required for protein transport from the endoplasmic reticulum to the Golgi apparatus in yeast. J Cell Biol, 107, 851-863.

Nichols, W.C., Seligsohn, U., Zivelin, A., Terry, V.H., Hertel, C.E., Wheatley, M.A., Moussalli, M.J., Hauri, H.P., Ciavarella, N., Kaufman, R.J., and Ginsburg, D. (1998) Mutations in the ER-Golgi intermediate compartment protein ERGIC-53 cause combined deficiency of coagulation factors V and VIII. Cell, 93, 61-70.

Nishimura, N., and Balch, W. (1997) A di-acidic signal required for selective export from the endoplasmic reticulum. Science, 277, 556-558.

Novick, P., and Schekman, R. (1979) Secretion and cell surface growth are blocked in a temperature sensitive mutant of Saccharomyces cerevisiae. Proc Natl Acad Sci USA, 76, 1858-1862.

Novick, P., and Schekman, R. (1983) Export of major cell surface proteins is blocked in yeast secretory mutants. J Cell Biol, 96, 541-547.

Novick, P., and Botstein, D. (1985) Phenotypic analysis of temperature-sensitive yeast actin mutants. Cell, 40, 405-416.

Novick, P., Field, C., and Schekman, R. (1980) The identification of 23 complementation groups required for post-translational events in the yeast secretory pathway. Cell, 21, 205-215.

Novick, P., Ferro, S., and Schekman, R. (1981) Order of events in the yeast secretory pathway. Cell, 25, 461-469.

Oliver, D.B., and Beckwith, J. (1981) E. coli mutant pleiotropically defective in the export of secreted proteins. Cell, 25, 765-772.

Olivera, B., and Bonhoeffer, F. (1972) Replication of $\varphi \mathrm{X} 174$ DNA by polA- in vitro. Proc Natl Acad Sci USA, 69, 25-29.

Orci, L., Ravazzola, M., Storch, M-J. Anderson, R., Vassalli, J-D., and Perrelet, A. (1987) Proteolytic maturation of insulin is a post-Golgi event which occurs in acidifying clathrin-coated secretory vesicles. Cell, 49, 865-868.

Orci, L., Ravazzola, M., Meda, P., Holcomb, C., Moore, H-P., Hicke, L., and Schekman, R. (1991) Mammalian Sec23p homologue is restricted to the endoplasmic reticulum transitional cytoplasm. Proc Natl Acad Sci USA, 88, 8611-8615.

Palade, G. (1975) Intracellular aspects of protein secretion. Science, 189, 347-358.

Payne, G.S., and Schekman, R. (1985) A test of clathrin function in protein secretion and cell growth. Science, 230, 1009-1014.

Payne, G.S., and Schekman, R. (1989) Clathrin: A role in the intracellular retention of a Golgi membrane protein. Science, 245, 1358-1365.

Pearse, B. (1976) Clathrin a unique protein associated with intracellular transfer of membrane by coated vesicles. Proc Natl Acad Sci USA, 73, 1255-1259.

Pelham, H. (1986) Speculations on the functions of the major heat shock and glucose-regulated proteins. Cell, 46, 959-961. 
Pryer, N.K., Salama, N.R., Schekman, R., and Kaiser, C.A. (1993) Cytosolic Sec13p complex is required for vesicle formation from the endoplasmic reticulum in vitro. J Cell Biol, 120, 865-875.

Redman, C., and Sabatini, D. (1966) Vectorial discharge of peptides released by puromycin from attached ribosomes. Proc Natl Acad Sci USA, 56, 608-615.

Redman, C, Siekevitz, P., and Palade, G. (1966) Synthesis and Transfer of Amylase in Pigeon Pancreatic Microsomes. J Biol Chem, 241, 1150-1158.

Rexach, M., and Schekman, R. (1991) Distinct biochemical requirements for the budding, targeting, and fusion of ER-derived transport vesicles. J Cell Biol, 114, 219-229.

Roberg, K., Crotwell, P., Espenshade, R., Gimeno, C., and Kaiser, C. (1999) LST1 is a SEC24 homologue used for selective export of the plasma membrane ATPase from the endoplasmic reticulum. J Cell Biol, 145, 659-672.

Roth, T., and Porter, K., (1964) Yolk protein uptake in the oocyte of the mosquito Aedes aegypti. J Cell Biol, 20, 313-331.

Rothblatt, J.A., Deshaies, R.J., Sanders, S., Daum, G., and Schekman, R. (1989) Multiple genes are required for proper insertion of secretory proteins into the endoplasmic reticulum in yeast. J Cell Biol, 109, 2641-2652.

Rothman, J., and Fine, R. (1980) Coated vesicles transport newly-synthesized membrane glycoproteins to plasma membrane in two successive stages. Proc Natl Acad Sci USA, 77, 280-284.

Ruohola, H., Kabcenell, A., and Ferro-Novick, S. (1988) Reconstitution of protein transport from the endoplasmic reticulum to the Golgi complex in yeast: The acceptor Golgi compartment is defective in the sec23 mutant. J Cell Biol, 107, 1465-1476.

Salama, N.R., Yeung, T., and Schekman, R. (1993) The Sec13p complex and reconstitution of vesicle budding from the ER with purified cytosolic proteins. EMBO $J, 12,4073-4082$.

Salminen, A., and Novick, P.J. (1987) A ras-like protein is required for a post-Golgi event in yeast secretion. Cell, 49, 527-538.

Schauer, I., Emr, S., Gross, C., and Schekman, R. (1985) Invertase signal and mature sequence substitutions that delay intercompartmental transport of active enzyme. J Cell Biol, 100, 1664-1675.

Schekman, R., and Singer, S.J. (1976) Clustering and endocytosis of membrane receptors can be induced in mature erythrocytes of neonatal humans but not adults. Proc Natl Acad Sci USA, 73, 4075-4079.

Schekman, R., and Brawley, V. (1979) Localized deposition of chitin on the yeast cell surface in response to mating pheromone. Proc Natl Acad Sci USA, 76, 645-649

Schekman, R.W., Wickner, W., Westergaard, O., Brutlag, D., Geider, K., Bertsch, L.L., and Kornberg, A. (1972) Initiation of DNA synthesis: synthesis of $\varphi$ X174 replicative form requires RNA synthesis resistant to rifampicin. Proc Natl Acad Sci USA, 69, 2691-2695.
Schekman, R., Weiner, A., and Kornberg, A. (1974) Multienzyme systems of DNA replication. Science, 186, 987-993.

Scott, J.H., and Schekman, R. (1980) Lyticase: Endoglucanase and protease activities that act together in yeast cell lysis. J Bact, 142, 414-423.

Semenza, J., Hardwick, K., Dean, N., and Pelham, H. (1990) ERD2, a yeast gene required for the receptormediated retrieval of ER luminal proteins from the secretory pathway. Cell, 61, 1349-1357.

Sheetz, M., and Singer, S.J. (1974) Biological membranes as bilayer couples. A mechanism of drug-erythrocyte interactions. Proc Natl Acad Sci USA, 71, 4457-4461.

Shiba, K., Ito, K., Yura, T., Cerretti, D.P. (1984) A defined mutation in the protein export gene within the spc ribosomal protein operon of Escherichia coli: isolation and characterization of a new temperature-sensitive secY mutant. EMBO J, 3, 631-635.

Shimoni, Y., Kurihara, T., Ravazzola, M., Amherdt, M., Orci, L., and Schekman, R. (2000) Lst1p and Sec24p cooperate in sorting of the plasma membrane ATPase into COPII vesicles in Saccharomyces cerevisiae. J Cell Biol, 151, 973-984.

Silhavy, T.J., Casadaban, M.J., Shuman, H.A., and Beckwith, J.R. (1976) Conversion of beta-galactosidase to a membrane-bound state by gene fusion. Proc Natl Acad Sci USA, 73, 3423-3427.

Singer, S.J., and Nicholson, G. (1972) The fluid mosaic model of membrane structure. Science, 175, 720-731.

Springer, S., and Schekman, R. (1998) Nucleation of COPII vesicular coat complex by ER to Golgi vSNAREs. Science, 281, 698-700.

Springer, S., Spang, A., and Schekman, R. (1999) A primer on vesicle budding. Cell, 97, 145-148.

Stagg, S.M., Gürkan, C., Fowler, D.M., LaPointe, P., Foss, T.R., Potter, C.S., Carragher, B., and Balch, W.E., (2006) Structure of the Sec13/31 COPII coat cage. Nature, 439, 234-238.

Stevens, T., Esmon, B., and Schekman, R. (1982) Early stages in the yeast secretory pathway are required for transport of carboxypeptidase $\mathrm{Y}$ to the vacuole. Cell, 30, 439-448.

Stirling, C.A., Rothblatt, J., Hosobuchi, M., Deshaies, R., and Schekman, R. (1992) Protein translocation mutants defective in the insertion of integral membrane proteins into the endoplasmic reticulum. Mol Biol Cell, 3, 129-142.

Supek, F., Madden, D.T., Hamamoto, S., Orci, L., and Schekman, R. (2002) Sec16p potentiates the action of COPII proteins to bud transport vesicles. J Cell Biol, 158, 1029-1038.

Thor, F., Gautschi, M., Geiger, R., and Helenius, A. (2009) Bulk flow revisited: Transport of a soluble protein in the secretory pathway. Traffic, 10, 1819-1830.

Tokuyasu, K. (1973) A technique for ultracryotomy of cell suspensions and tissues. J Cell Biol, 57, 551-565.

Valenzuela, P., Medina, M, Rutter, W., Ammerer, G., and Hall, B. (1982) Synthesis and assembly of hepatitis B surface antigen particles in yeast. Nature, 298, 347-350. 
Wansleeben, C., Feitsma, H., Montcouquiol, M., Kroon, C., Cuppen, E., and Meljlink, F. (2010) Planar cell polarity defects and defective Vangl2 trafficking in mutants for the COPII gene Sec24b. Development, 137, 1067-1073.

Watson, J.D. (1966) The Molecular Biology of the Gene. W.A. Benjamin, New York.

Wickner, W., Brutlag, D., Schekman, R., and Kornberg, A. (1972) RNA synthesis initiates in vitro conversion of M13 DNA to its replicative form. Proc Natl Acad Sci USA, 69, 965-969.

Wieland, F., Gleason, M., Serafini, T., and Rothman, J. (1987) The rate of bulk flow from the endoplasmic reticulum to the cell surface. Cell, 50, 289-300.

Wilson, D.W., Wilcox, C.A., Flynn, G.C., Chen, E., Kuang, W.J., Henzel, W.J., Block, M.R., Ullrich, A., and Rothman, J.E. (1989) A fusion protein required for vesicle-mediated transport in both mammalian cells and yeast. Nature, 339, 355-359.
Wu, J., and Mlodzik, M. (2009) A quest for the mechanism regulating global planar cell polarity. Trends Cell Biol, 19, 295-305.

Yeung, T., Barlowe, C., and Schekman, R. (1995) Uncoupled packaging of targeting and cargo molecules during transport vesicle budding from the endoplasmic reticulum. J Biol Chem, 270, 30567-30570.

Yoshihisa, T., Barlowe, C., and Schekman, R. (1993) Requirement for a GTPase-activating protein in vesicle budding from the endoplasmic reticulum. Science, 259, 1466-1468.

Zanetti, G., Pahuja, K. B, Studer, S., Shim, S., and Schekman, R. (2011) COPII and the regulation of protein sorting in mammals. Nature Cell Biol, 14, 20-28.

Zanetti, G., Prinz, S., Daum, S., Meister, A., Schekman, R., Bacia, K., and Briggs, J.A.G. (2013) The structure of the COPII coat assembled on membranes. Elife, Sep 17,2 , e00951. 